\title{
Coherent Three-Pulse Spectroscopy of Coupled Vibrations in a Rigid Dipeptide: Density Functional Theory Simulations
}

\author{
Jens Dreyer, ${ }^{* \dagger}$ Andrew M. Moran, and Shaul Mukamel* \\ Department of Chemistry, Department of Physics and Astronomy, University of Rochester, \\ Rochester, New York 14627-0216
}

Received: January 27, 2003

The full quartic six-mode force field for the $\mathrm{NH}, \mathrm{CO}$, and $\mathrm{CN}$ stretches of the peptide bonds of a cyclic dipeptide rigidly held by a bridge (2,5-diazabicyclo[2,2,2]octane-3,6-dione (DABCODO)) is computed at the $\mathrm{ab}$ initio level and used for the simulation of two-dimensional three-pulse femtosecond infrared measurements. Analysis of the complete set of one- and two-color signals generated at all four possible wavevectors $\left(-\mathbf{k}_{1}+\mathbf{k}_{2}+\mathbf{k}_{3}, \mathbf{k}_{1}-\mathbf{k}_{2}+\mathbf{k}_{3}, \mathbf{k}_{1}+\mathbf{k}_{2}-\mathbf{k}_{3}, \mathbf{k}_{1}+\mathbf{k}_{2}+\mathbf{k}_{3}\right)$ shows distinct signatures of anharmonicities, mode couplings, Fermi resonances, and relative transition dipole orientations.

\section{Introduction}

Multidimensional vibrational spectroscopy provides new insights into structural and dynamical properties of molecules and chemical reactions with ultrafast time resolution. ${ }^{1-3}$ Congested ordinary one-dimensional (1D) spectra may be disentangled by spreading the signal into additional dimensions, allowing the time scales of environmental bath interactions to be discerned by line shape analysis. $n \mathrm{D}$ techniques are based on correlation plots displaying the signal with respect to $n$ variables. These may include time intervals between pulses $\left(t_{j}\right)$, carrier frequencies $\left(\bar{\omega}_{n}\right)$, or other pulse parameters such as envelopes, polarizations, durations, and even phases. ${ }^{4-6}$ Newly appearing cross-peaks in two-dimensional correlation plots contain direct signatures of intra- or intermolecular interactions that can be converted into structural and dynamical information. Intense tunable 50-100 fs infrared pulses make it possible to monitor structural changes and ultrafast processes such as vibrational energy relaxation and redistribution, charge transfer, conformational fluctuations, and chemical reactions.

Linear-infrared spectroscopy has been widely used to study secondary structures of peptides and proteins, because many vibrational bands of the amide units are sensitive to structure. ${ }^{7-8}$ These include the amide I band, mainly a carbonyl stretching vibration with contributions from the $\mathrm{C}^{\prime}-\mathrm{N}$ stretch and $\mathrm{C}^{\prime}-\mathrm{N}-\mathrm{H}$ bend; the amide II mode $\left(1600-1700 \mathrm{~cm}^{-1}\right),{ }^{8}$ predominantly the $\mathrm{C}^{\prime}-\mathrm{N}$ stretch coupled with the $\mathrm{C}-\mathrm{N}-\mathrm{H}$ bend; and the $\mathrm{N}-\mathrm{H}$ stretch, which is split into the amide A and B bands (3100 and $3300 \mathrm{~cm}^{-1}$ ) due to a Fermi resonance with the first overtone of the amide II mode. ${ }^{9}$ In recent years, experimental multidimensional IR techniques have been applied toward the study of peptides and small molecules. ${ }^{10-34}$ Double resonance pumpprobe methods with frequency selective excitation (pump) and broad band probe pulses have been used in initial studies of vibrational coupling and energy transfer in small oligopeptides. ${ }^{10}$ More recently, guidelines for the mapping of strong field NMR pulse sequences into weak field optical techniques have been established $^{35,36}$ and pure time domain heterodyned two- and

\footnotetext{
* To whom correspondence should be addressed. Electronic address: dreyer@mbi-berlin.de and mukamel@chem.rochester.edu.

Max-Born-Institut für Nichtlineare Optik und Kurzzeitspektroskopie, D-12489 Berlin, Germany.
}

three-pulse IR analogues of the NMR COSY and NOESY pulse sequences have been implemented. ${ }^{13}$

Peptides usually have a complex energy landscape with many local minima corresponding to various secondary structures, ${ }^{37-40}$ a number of which are relevant to the description of folding dynamics. Multidimensional infrared and Raman techniques have the potential to probe rapidly changing structural elements such as $\alpha$ helices and $\beta$ sheets with subpicosecond resolution. A key ingredient in the design and interpretation of these measurements is the ability to predict force fields at the ab initio level. Force fields employed in standard packages are not parametrized to calculate anharmonicities and yield conflicting results for small peptides. ${ }^{41}$

The purpose of this paper is to provide a simple benchmark for the application of ab initio methodology for predicting nonlinear-infrared response of peptides. Small peptides usually do not have a well-defined structure because their potential surface possesses many local minima. ${ }^{42} \mathrm{We}$ found the dipeptide 2,5-diazabicyclo[2,2,2] octane-3,6-dione (DABCODO), a cyclic

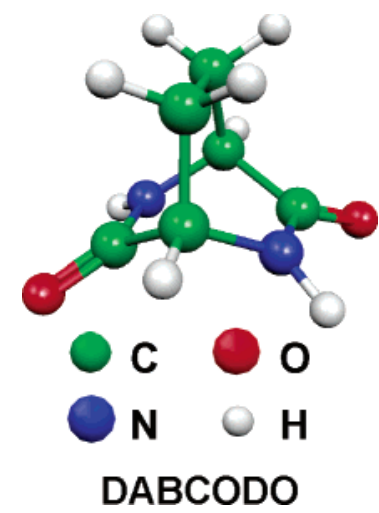

diglycine with an ethano bridge, ${ }^{43}$ to be an ideal model system for our simulations. It exists in a single and rather rigid conformation so that the structure in the gas phase as well as in solution is unambiguous. Also, the molecule is sufficiently small to allow high-level ab initio quantum chemical calculations of the vibrational eigenstates and anharmonic couplings. ${ }^{44}$

The first-principles simulation of multidimensional signals requires the calculation of optical response functions. In the first 
step, internal coordinates (local modes) are chosen to describe local vibrational motions; bond lengths represent stretching vibrations, bond angles represent in-plane bending modes, and dihedral angles represent out-of-plane vibrations. Anharmonic force constants and dipole derivatives for selected local modes are then calculated by numerical differentiation of the energy and dipole to fourth and second order, respectively. Diagonalization of the resulting effective vibrational exciton Hamiltonian yields molecular eigenstates, eigenvectors, and transition dipole moments between all states. Third-order nonlinear response functions are then computed in the time domain using the sumover-states expression. ${ }^{45}$ This procedure was tested in a recent simulation of the photon echo spectrum of a rhodium(I)dicarbonyl complex using the B3LYP density functional and the LanLDZ basis set. Qualitative agreement was found with experiment, ${ }^{28}$ and quartic terms in the potential energy were shown to be critical for reproducing the experimental transition energies and intensities. We present simulations of the signals generated at the four possible independent signal wavevectors and analyze the information that may be extracted from the cross-peak pattern for each signal using both one- and twocolor pulse techniques.

\section{Nonlinear Response Functions and Multidimensional Signals}

Third-order nonlinear multidimensional vibrational spectroscopy involves the application of three pulses $\left(\tau_{1}-\tau_{3}\right)$ that

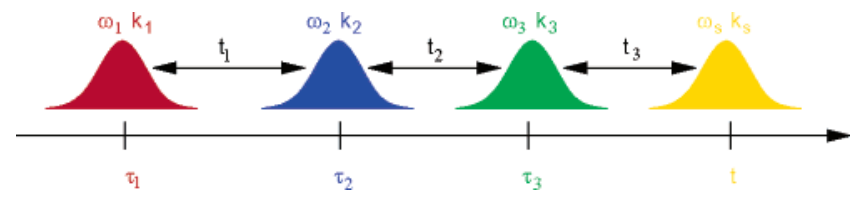

create and manipulate populations and coherences of vibrational states. $^{2,45}$ The total electric field at point $r$ is given by

$$
\begin{aligned}
\mathscr{S}(\mathbf{r}, \tau)=\sum_{n=1}^{3}\left[\mathcal{O}_{n}\left(\tau-\tau_{n}\right) \exp \left(\mathbf{i} \mathbf{k}_{n} \mathbf{r}-\mathrm{i} \omega_{n} \tau+\mathrm{i} \varphi_{n}\right) \times\right. \\
\left.\mathcal{O}_{n}^{*}\left(\tau-\tau_{n}\right) \exp \left(-\mathrm{i} \mathbf{k}_{n} \mathbf{r}+\mathrm{i} \omega_{n} \tau-\mathrm{i} \varphi_{n}\right)\right]
\end{aligned}
$$

with an envelope $\mathscr{O}_{n}\left(\tau-\tau_{n}\right)$ centered at $\tau_{n}$, a carrier frequency $\bar{\omega}_{n}$, a phase $\varphi_{n}$, and a wavevector $\mathbf{k}_{n}$ of the $n$th pulse. The thirdorder polarization vector induced by this field is

$$
\begin{aligned}
& P_{i}^{(3)}(\mathbf{r}, t)=\int_{0}^{\infty} \mathrm{d} t_{1} \int_{0}^{\infty} \mathrm{d} t_{2} \int_{0}^{\infty} \mathrm{d} t_{3} R_{i j k l}^{(3)}\left(t_{3}, t_{2}, t_{1}\right) \times \\
& \mathcal{O}_{j}\left(\mathbf{r}, \tau_{3}=t-t_{3}\right) \mathcal{O}_{k}\left(\mathbf{r}, \tau_{2}=t-t_{3}-t_{2}\right) \mathcal{O}_{l}\left(\mathbf{r}, \tau_{1}=t-t_{3}-t_{2}-t_{1}\right)
\end{aligned}
$$

where $i, j, k, l \in\{x, y, z\}$ refer to the Cartesian components of the linearly polarized electric field and polarization. $t_{1}$ and $t_{2}$ are the delay times between the three pulses, and $t_{3}$ is the time between the third pulse and the time $t$ when the signal is finally measured. Controlling $t_{3}$ requires an additional gating device or heterodyne detection. The nonlinear polarization is characterized by a response function $R_{i j k l}^{(3)}$, a fourth-rank tensor that contains the full microscopic information about all third-order signals.

Substituting eq 1 into eq 2 shows that a signal can be generated in eight possible wavevector directions $\mathbf{k}_{S}= \pm \mathbf{k}_{1} \pm$ $\mathbf{k}_{2} \pm \mathbf{k}_{3}$. Coherent three-pulse spectroscopies may be distinguished and systemically classified in terms of the signal wavevectors that represent distinct combinations of Liouville space pathways. ${ }^{2,45}$ The details of a particular experiment are contained in the external field profiles $\mathscr{O}_{n}(t)$, eq 1 , and in the particular choice of $\mathbf{k}_{S}$, which selects specific Liouville space pathways. Thus, only at this stage, the different spectroscopic techniques may be distinguished. Only four signal wavevectors $\mathbf{k}_{S}$ are independent and will be denoted $\mathbf{k}_{\mathrm{I}}=-\mathbf{k}_{1}+\mathbf{k}_{2}+\mathbf{k}_{3}$, $\mathbf{k}_{\mathrm{II}}=+\mathbf{k}_{1}-\mathbf{k}_{2}+\mathbf{k}_{3}, \mathbf{k}_{\mathrm{III}}=+\mathbf{k}_{1}+\mathbf{k}_{2}-\mathbf{k}_{3}$, and $\mathbf{k}_{\mathrm{IV}}=+\mathbf{k}_{1}+$ $\mathbf{k}_{2}+\mathbf{k}_{3}$. The remaining four wavevectors are given by $-\mathbf{k}_{S}$. It follows from eq 1 that each choice of $\mathbf{k}_{S}$ also implies a particular combination of field frequencies $\bar{\omega}_{\mathrm{s}}= \pm \bar{\omega}_{1} \pm \bar{\omega}_{2} \pm \bar{\omega}_{3}$.

$R_{i j k l}^{(3)}$ is generally given as a sum of eight four-point correlation functions of the dipole operator, each representing a distinct Liouville space pathway. Only four out of the eight terms contributing to the response function are independent, the other four are given by their complex conjugates:

$$
\begin{aligned}
R_{i j k l}^{(3)}\left(t_{3}, t_{2}, t_{1}\right) & =\left(\frac{i}{\hbar}\right)^{3}\left\langle\left[\mu_{i}\left(t_{3}+t_{2}+t_{1}\right),\left[\mu_{j}\left(t_{2}+t_{1}\right),\left[\mu_{k}\left(t_{1}\right), \mu_{l}(0)\right]\right]\right]\right\rangle \\
& =\left(\frac{i}{\hbar}\right)^{3} \sum_{\alpha=1}^{4}\left(R_{\alpha}\right)_{i j k l}\left(t_{3}, t_{2}, t_{1}\right)+\mathrm{cc}
\end{aligned}
$$

with

$$
\begin{aligned}
& \left(R_{1}\right)_{i j k l}\left(t_{3}, t_{2}, t_{1}\right)= \\
& \sum_{a, b, c, d} P(a)\left\langle i_{c d} j_{b c} k_{a b} l_{d a}\right\rangle \mu_{a b} \mu_{b d} \mu_{c d} \mu_{d a} I_{d c}\left(t_{3}\right) I_{d b}\left(t_{2}\right) I_{d a}\left(t_{1}\right) \\
& \left(R_{2}\right)_{i j k l}\left(t_{3}, t_{2}, t_{1}\right)= \\
& \sum_{a, b, c, d} P(a)\left\langle i_{c d} j_{b c} k_{d a} l_{a b}\right\rangle \mu_{a b} \mu_{b c} \mu_{c d} \mu_{d a} I_{d c}\left(t_{3}\right) I_{d b}\left(t_{2}\right) I_{a b}\left(t_{1}\right) \\
& \left(R_{3}\right)_{i j k l}\left(t_{3}, t_{2}, t_{1}\right)= \\
& \sum_{a, b, c, d} P(a)\left\langle i_{c d} j_{d a} k_{b c} l_{a b}\right\rangle \mu_{a b} \mu_{b c} \mu_{c d} \mu_{d a} I_{d c}\left(t_{3}\right) I_{a c}\left(t_{2}\right) I_{a b}\left(t_{1}\right) \\
& \left(R_{4}\right)_{i j k l}\left(t_{3}, t_{2}, t_{1}\right)= \\
& \sum_{a, b, c, d} P(a)\left\langle i_{a b} j_{b c} k_{c d} l_{d a}\right\rangle \mu_{a b} \mu_{b c} \mu_{c d} \mu_{d a} I_{b a}\left(t_{3}\right) I_{c a}\left(t_{2}\right) I_{d a}\left(t_{1}\right)
\end{aligned}
$$

and the line shape function

$$
I_{v v^{\prime}}(t)=\theta(t) \exp \left(-\mathrm{i} \Omega_{v v^{\prime}} t-\Gamma_{v v^{\prime}} t\right)
$$

$\Omega_{v v^{\prime}}$ constitute transition frequencies between two vibrational eigenstates $v$ and $v^{\prime}, \Gamma_{v v^{\prime}}$ is a homogeneous dephasing line width, and $\mu_{v v^{\prime}}$ are the corresponding transition dipole moments describing the coupling between the states. $\theta(t)$ is the Heavyside function, and $P(a)$ is the thermal population of the initial state $a$ given as Boltzmann factor

$$
P(a)=\frac{\exp \left(-\epsilon_{a} / k_{\mathrm{B}} T\right)}{\sum_{a} \exp \left(-\epsilon_{\mathrm{a}} / k_{\mathrm{B}} T\right)}
$$

More sophisticated simulations of environmental effects affecting the signal line shapes ${ }^{46}$ will be incorporated in future work as the main objective of the current study is to identify the main peaks and analyze the possible global patterns of multidimensional signals.

If orientational and vibrational dynamics are decoupled, each of the terms contributing to the response function containes a scalar part describing the vibronic dynamics and a fourth rank tensorial part, the ensemble average $\langle i j k l\rangle$, of the orientational 


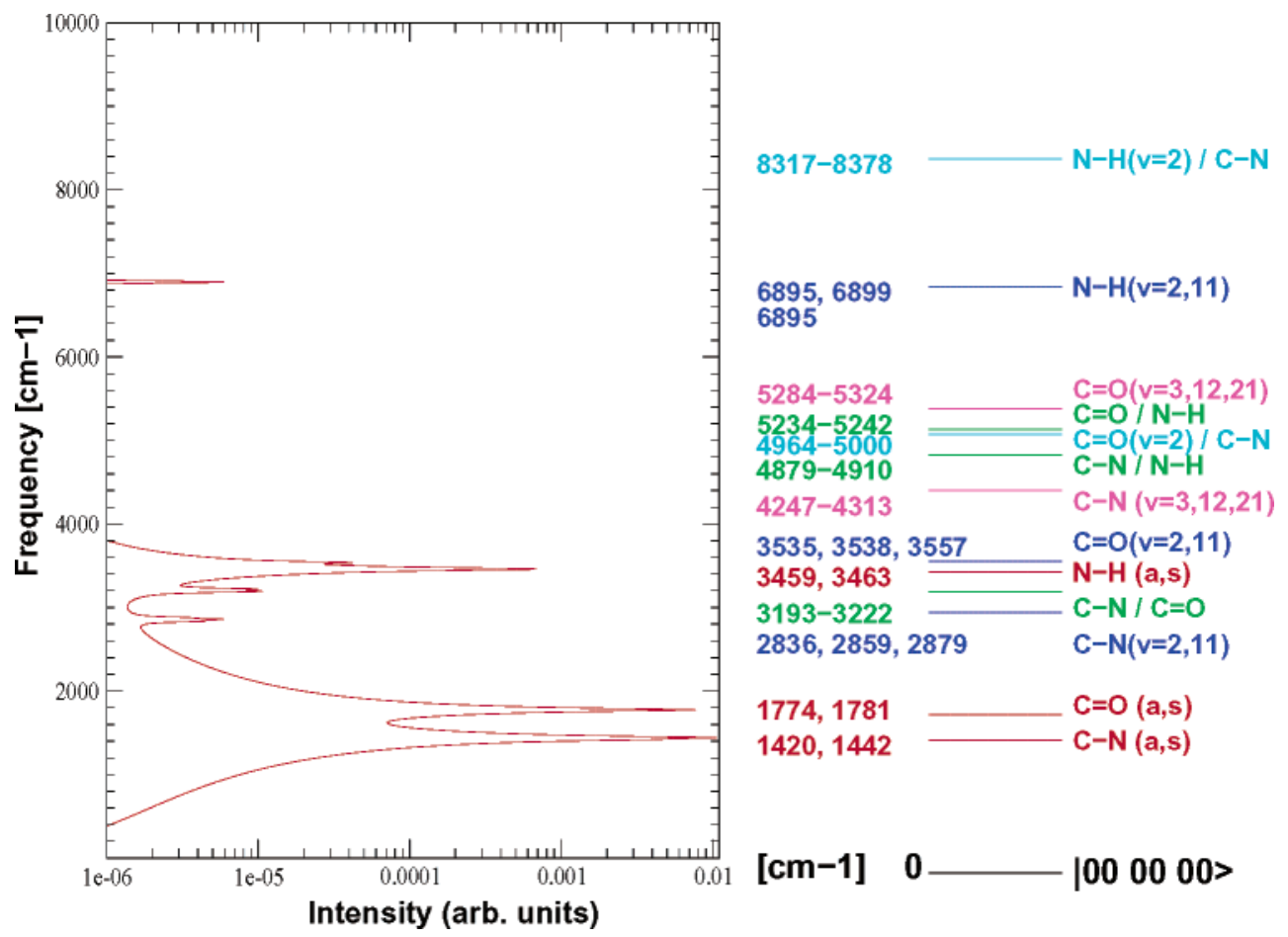

Figure 1. Logarithmic linear IR spectrum of DABCODO and the energy level scheme calculated from eigenstates and transition dipole moments of the six-mode exciton Hamiltonian $\left(\Gamma=5 \mathrm{~cm}^{-1}\right)$. One exciton states (red) consist of two individual levels, single-mode two-exciton states (blue) of three levels, mixed two-exciton states (green) of four levels, single-mode three-exciton states (magenta) of three levels, and mixed three-exciton states (light blue) consist of four levels.

factor of the response. ${ }^{26,47,48}$ This factor, introduced in eq 4 relates the orientation of the electric field of the four pulses in the laboratory frame $(i, j, k, l \in\{x, y, z\})$ to the orientation of four transition dipole moment vectors involved in each Liouville space pathway. ${ }^{49,50} \mathrm{We}$ assume that rotational dynamics is slow on the experimental time scale, which is typically justified for subpicosecond measurements in polyatomic molecules. Otherwise, the orientational factor will become time dependent as well. ${ }^{26,45}$

A full simulation of the signals should include the response function as well as the pulse shapes. We have made our calculations in the snapshot limit, ${ }^{45}$ which incorporates the key pulse characteristics at a greatly reduced computational cost. In this ideal limit of time-domain impulsive experiments, all the applied fields are taken to be very short (impulsive) so that the integrations over time intervals can be eliminated and the signal is directly proportional to the nonlinear response function. At the same time a finite (rectangular) pulse bandwidth allows a spectral selection of the resonant transitions of interest.

When the pulse envelopes are incorporated in the triple integrals, all signals may be computed using the full response functions. The time integrations automatically select the dominant terms for each possible technique. Because our simplified procedure does not include these integrations, the rotating wave approximation (RWA) must be applied manually to select only those terms that are resonant; that is, the material frequency $\Omega_{v v^{\prime}}$ must reside within the field bandwidth around $\bar{\omega}_{n}$. All nonresonant and highly oscillating terms must be neglected. Eliminating the integrations without invoking the RWA leads to incorrect results because it implies that the pulses are short compared with the carrier frequency, which is, of course, impossible. The terms that survive the RWA depend on the molecular level scheme as well as the dipole couplings. We shall denote the RWA response function for a specific choice of the wavevector $\mathbf{k}_{S}$ in a three-pulse impulsive experiment as $\mathscr{R}_{i j k l}^{S}\left(t_{3}, t_{2}, t_{1}\right)$ with $S=\mathrm{I}$, II, III, IV.

Various detection modes may be employed. ${ }^{2}$ The time-gated homodyne detected signal is directly given by $\left|\mathscr{R}_{i j k l}^{S}\left(t_{3}, t_{2}, t_{1}\right)\right|^{2}$. The signal can also be displayed in the frequency domain: Using a two-dimensional Fourier transformation for the time variables $t_{1}$ and $t_{3}$, we obtain the complex signal

$$
\begin{aligned}
& S\left(\omega_{3}, t_{2}, \omega_{1}\right)= \\
& \quad \int_{-\infty}^{\infty} \mathrm{d} t_{3} \int_{-\infty}^{\infty} \mathrm{d} t_{1} \mathscr{R}_{i j k l}^{S}\left(t_{3}, t_{2}, t_{1}\right) \exp \left(-\mathrm{i} \omega_{3} t_{3}-\mathrm{i} \omega_{1} t_{1}\right)
\end{aligned}
$$

similarly transforming $t_{2}$ and $t_{3}$ yields

$$
\begin{aligned}
& S\left(\omega_{3}, \omega_{2}, t_{1}\right)= \\
& \quad \int_{-\infty}^{\infty} \mathrm{d} t_{3} \int_{-\infty}^{\infty} \mathrm{d} t_{1} R_{i j k l}^{S}\left(t_{3}, t_{2}, t_{1}\right) \exp \left(-\mathrm{i} \omega_{3} t_{3}-\mathrm{i} \omega_{2} t_{2}\right)
\end{aligned}
$$

These signals will be computed in the coming sections.

\section{Anharmonic Force Field and the Exciton Hamiltonian}

The geometry of DABCODO has been optimized using density functional theory (B3LYP $)^{51-54}$ with a 6-31G(d,p) basis set $^{55-59}$ implemented in Gaussian98. ${ }^{60}$ The resulting $C_{2}$-symmetric structure was in very good agreement with that reported previously. ${ }^{43}$

Anharmonic force constants representing the complete quartic force field and first-order dipole derivatives have been calculated numerically following the procedure described earlier. ${ }^{44}$ Only internal coordinates representing the predominant contributions to the amide I, II, A, and B modes were selected (Table 1). The amide I and II modes are described by the $\mathrm{C}=\mathrm{O}$ and $\mathrm{C}-\mathrm{N}$ stretches, respectively. The $\mathrm{C}^{\prime}-\mathrm{N}-\mathrm{H}$ and $\mathrm{C}_{\alpha}-\mathrm{C}^{\prime}-\mathrm{N}$ bending 

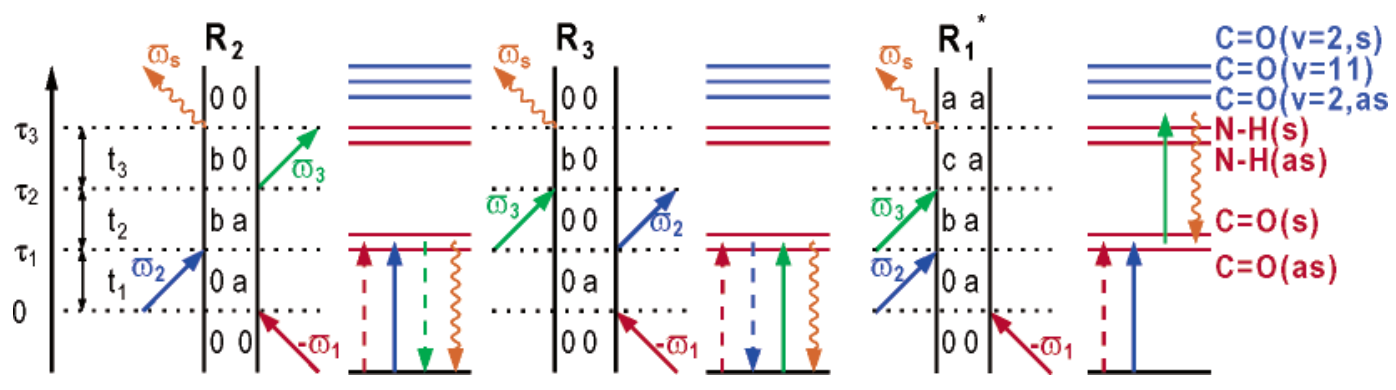

Figure 2. $\mathbf{k}_{\mathrm{I}}=-\mathbf{k}_{1}+\mathbf{k}_{2}+\mathbf{k}_{3}$ : Feynman diagrams $\left(\mathscr{R}_{\mathrm{s}}=\mathrm{R}_{2}+\mathrm{R}_{3}-\mathrm{R}_{1}^{*}\right)$ and energy level schemes (dashed arrows, interaction from the right; solid arrows, interaction from the left; wavy arrows, signal pulse) for $\bar{\omega}_{1}=\bar{\omega}_{2}=\bar{\omega}_{3}=1770 \mathrm{~cm}^{-1}(v(\mathrm{C}=\mathrm{O}))$. For a pulse width of $\pm 100 \mathrm{~cm}-1$ the following number of Liouville space pathways result: $\mathrm{R}_{2}$ and $\mathrm{R}_{3}, 4$ each; $\mathrm{R}_{1}^{*}, 20$.
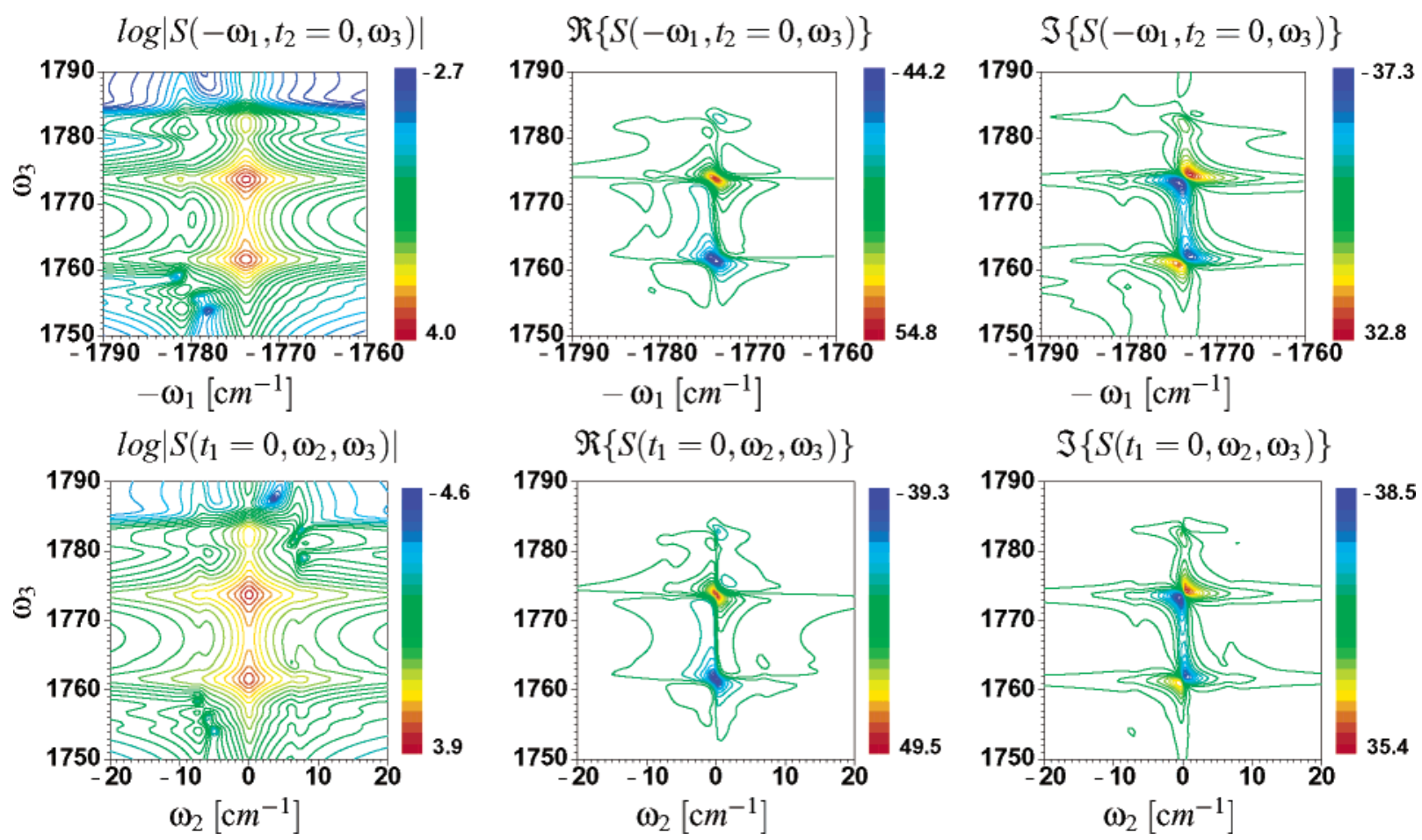

Figure 3. $\mathbf{k}_{\mathrm{I}}$ : $2 \mathrm{D} \operatorname{spectra}(z z z z)$ for $\bar{\omega}_{1}=\bar{\omega}_{2}=\bar{\omega}_{3}=1770 \mathrm{~cm}^{-1}(\nu(\mathrm{C}=\mathrm{O}))$. Upper panel: $t_{2}=0$. Lower panel: $t_{1}=0$.

TABLE 1: Selected Internal Coordinates for Each Peptide Unit with Intrinsic Frequencies $\tilde{\omega}_{k}$

\begin{tabular}{ccccc}
\hline no. & coordinate & amide band & bond length $(\mathrm{pm})$ & $\tilde{\omega}_{k}{ }^{a}$ \\
\hline 1 & $\mathrm{C}=\mathrm{O}$ & I & 121.9 & 1786.5 \\
2 & $\mathrm{~N}-\mathrm{C}$ & II & 136.8 & 1468.4 \\
3 & $\mathrm{~N}-\mathrm{H}$ & $\mathrm{A}, \mathrm{B}$ & 101.0 & 3644.1
\end{tabular}

${ }^{a}$ Diagonal element of the quadratric force constant matrix.

modes carry significant amplitudes in the amide I and in particular in the amide II modes. These coordinates were neglected, causing small deviations from the vibrational frequencies calculated in a $3 N-6$ coordinate harmonic normalmode analysis. Nonetheless, an accurate description of the spectra is retained as the intensities of these modes are derived primarily from the $\mathrm{C}=\mathrm{O}$ and $\mathrm{C}-\mathrm{N}$ dipole derivatives.

A Fermi resonance of the amide II overtone with the fundamental of the $\mathrm{N}-\mathrm{H}$ stretch gives rise to the amide $\mathrm{A}$ $\left(\approx 3300 \mathrm{~cm}^{-1}\right)$ and amide $\mathrm{B}\left(\approx 3100 \mathrm{~cm}^{-1}\right)$ bands. ${ }^{9}$ The former carries about $90 \%$ of the total intensity and is mostly composed of a single excitation in the $\mathrm{N}-\mathrm{H}$ stretch. ${ }^{61} \mathrm{We}$ did not calculate a Fermi resonance, because the $\mathrm{N}-\mathrm{H}$ stretch frequency is overestimated by DFT and at the same time the amide II
TABLE 2: Eigenstates of Fundamental Transitions of the Six-Mode Hamiltonian (10 Excitation Quanta)

\begin{tabular}{lcccc}
\hline & \multicolumn{2}{c}{ energy } & eigenvector: $|\mathrm{CN} \mathrm{CN} \mathrm{CO} \mathrm{CO} \mathrm{NH} \mathrm{NH}\rangle$ \\
\hline & 0.0 & 0.98 & $|000000\rangle$ \\
$v_{\mathrm{s}}(\mathrm{C}-\mathrm{N})$ & $\Omega_{\mathrm{e}}$ & $1420.4+0.38$ & $|100000\rangle+0.86|010000\rangle$ \\
$\nu_{\mathrm{as}}(\mathrm{C}-\mathrm{N})$ & $\Omega_{\mathrm{f}}$ & $1441.7+0.86$ & $|100000\rangle-0.38|010000\rangle$ \\
$\nu_{\mathrm{as}}(\mathrm{C}=\mathrm{O})$ & $\Omega_{\mathrm{a}}$ & $1773.6+0.65$ & $|001000\rangle-0.66|000100\rangle$ \\
$\nu_{\mathrm{s}}(\mathrm{C}=\mathrm{O})$ & $\Omega_{\mathrm{b}}$ & $1780.8-0.66$ & $|001000\rangle-0.65|000100\rangle$ \\
$v_{\mathrm{as}}(\mathrm{N}-\mathrm{H})$ & $\Omega_{\mathrm{c}}$ & $3458.9-0.61$ & $|000010\rangle+0.73|000001\rangle$ \\
$v_{\mathrm{s}}(\mathrm{N}-\mathrm{H})$ & $\Omega_{\mathrm{d}}$ & $3463.6-0.71$ & $|000010\rangle-0.59|000001\rangle$
\end{tabular}

frequency, which misses the contribution from the $\mathrm{N}-\mathrm{H}$ bending vibration, is underestimated. In addition, solvation increases (decreases) the amide II (amide A) frequencies, reducing the energy gap between the interfering states and enhancing the Fermi resonances. ${ }^{62}$ Our calculations are performed in vacuo and therefore do not account for this effect.

The anharmonic exciton Hamiltonian has been recast in a normally ordered second quantized form for the 6 local modes. A sum of 10 excitation quanta over all basis states results in a total number of 2153 basis states. ${ }^{44}$ Table 2 summarizes the eigenvectors of the fundamental (one-exciton) transitions. Energies and anharmonic shifts are collected in Table 3 for all 


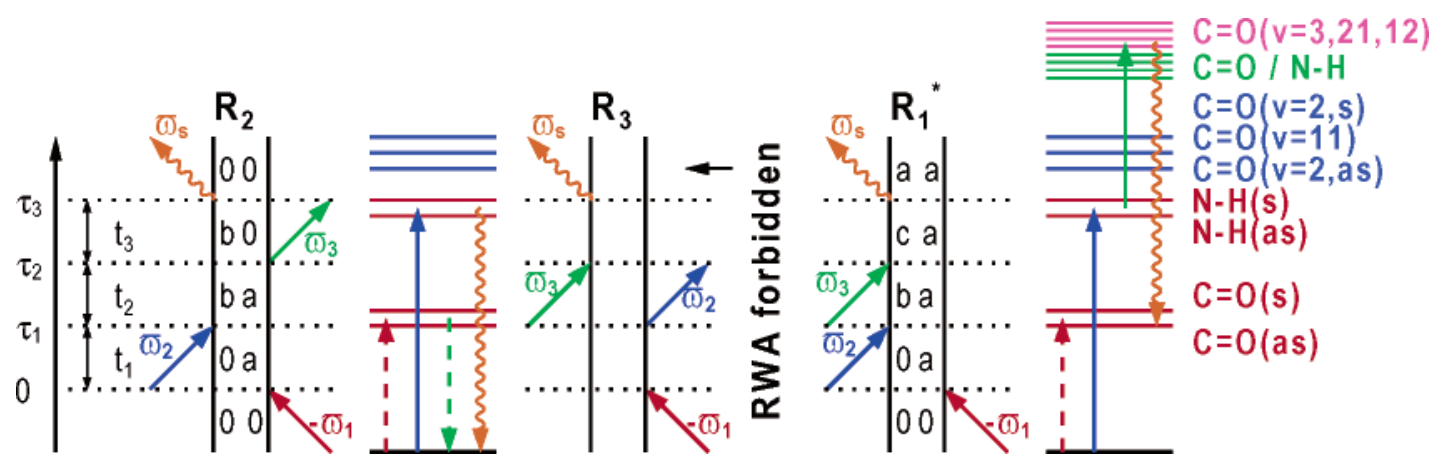

Figure 4. $\mathbf{k}_{\mathrm{I}}$ : Feynman diagrams $\left(\mathscr{R}_{\mathrm{s}}=\mathrm{R}_{2}+\mathrm{R}_{3}-\mathrm{R}_{1}^{*}\right)$ and energy level schemes for $\bar{\omega}_{1}=\bar{\omega}_{3}=1770 \mathrm{~cm}^{-1}(\nu(\mathrm{C}=\mathrm{O})), \bar{\omega}_{2}=3461 \mathrm{~cm}^{-1}$ $(v(\mathrm{~N}-\mathrm{H})) . \mathrm{R}_{2}: 10$ pathways. $\mathrm{R}_{3}$ : forbidden in the RWA. $\mathrm{R}_{1}^{*}$ : 80 pathways. Pulse width $= \pm 100 \mathrm{~cm}^{-1}$.
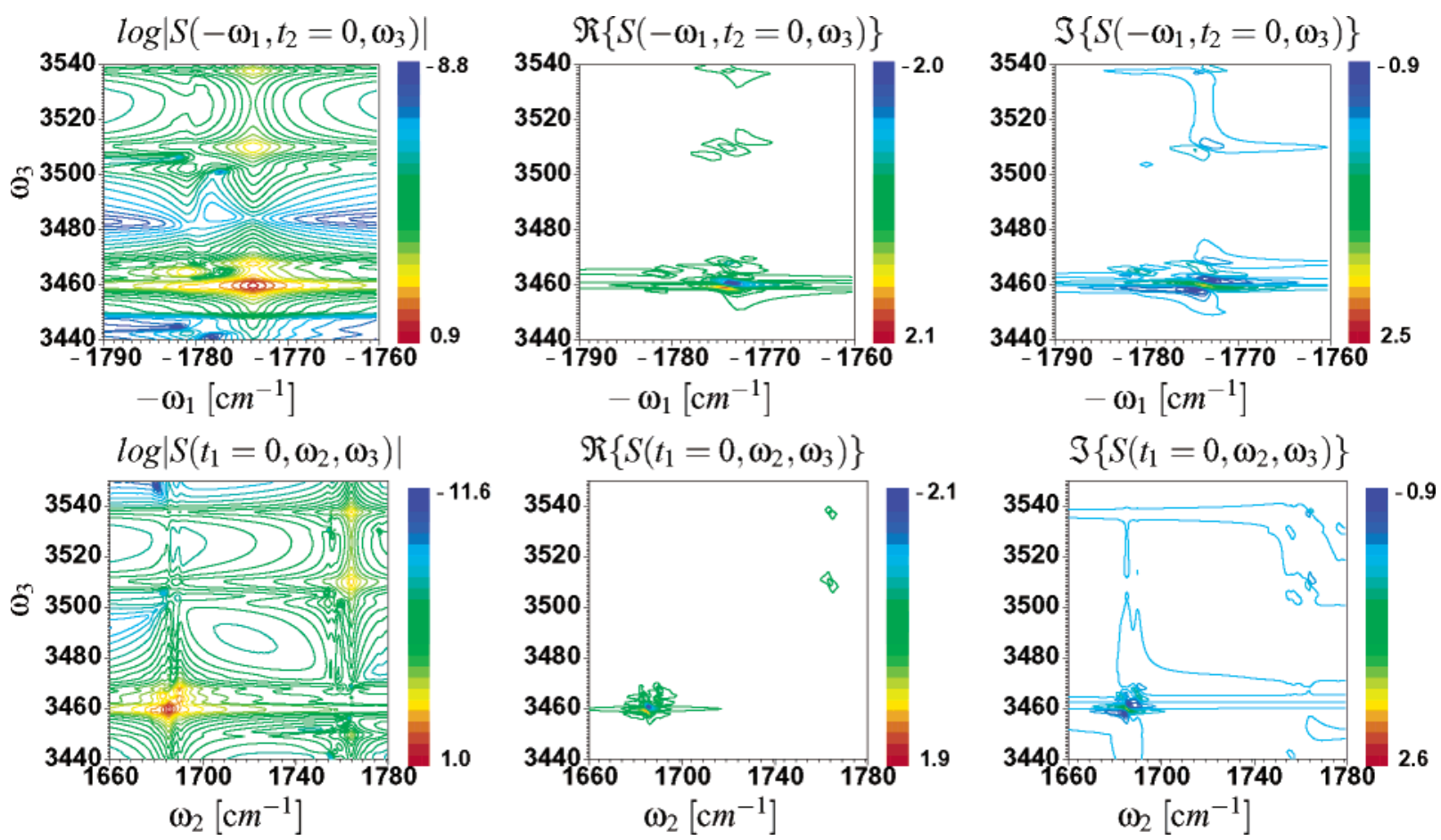

Figure 5. $\mathbf{k}_{\mathrm{I}}$ : $2 \mathrm{D}$ spectra $(z z z z)$ for $\bar{\omega}_{1}=\bar{\omega}_{3}=1770 \mathrm{~cm}^{-1}(v(\mathrm{C}=\mathrm{O})), \bar{\omega}_{2}=3461 \mathrm{~cm}^{-1}(v(\mathrm{~N}-\mathrm{H}))$. Upper panel: $t_{2}=0$. Lower panel: $t_{1}=0$.

TABLE 3: Local Mode Intrinsic Frequencies $\tilde{\omega}_{\mathrm{k}}$ (Unscaled), Eigenstate Energies for Fundamental Transitions $\boldsymbol{\Omega}_{j}$, and Anharmonic Shifts for Overtone $\left(\Delta_{i i}\right)$ and Combination Bands $\left(\Delta_{i j}\right)\left(\mathbf{c m}^{-1}\right)$

\begin{tabular}{cccr}
\hline parameter & energy & parameter & energy \\
\hline$\tilde{\omega}_{1}$ & 1468.4 & $\Delta_{\mathrm{ab}}$ & 16.9 \\
$\tilde{\omega}_{2}$ & 1468.4 & $\Delta_{\mathrm{cd}}$ & 2.4 \\
$\tilde{\omega}_{3}$ & 1786.5 & $\Delta_{\mathrm{ef}}$ & 3.4 \\
$\tilde{\omega}_{4}$ & 1786.5 & $\Delta_{\mathrm{ea}}$ & 1.2 \\
$\tilde{\omega}_{5}$ & 3644.1 & $\Delta_{\mathrm{eb}}$ & 0.9 \\
$\tilde{\omega}_{6}$ & 3644.1 & $\Delta_{\mathrm{fa}}$ & 1.4 \\
$\Omega_{\mathrm{e}}$ & 1420.4 & $\Delta_{\mathrm{fb}}$ & 0.5 \\
$\Omega_{\mathrm{f}}$ & 1441.7 & $\Delta_{\mathrm{ec}}$ & \pm 0.0 \\
$\Omega_{\mathrm{a}}$ & 1773.8 & $\Delta_{\mathrm{ed}}$ & -3.1 \\
$\Omega_{\mathrm{b}}$ & 1780.8 & $\Delta_{\mathrm{fc}}$ & 0.8 \\
$\Omega_{\mathrm{c}}$ & 3458.9 & $\Delta_{\mathrm{fd}}$ & -5.3 \\
$\Omega_{\mathrm{d}}$ & 3463.6 & $\Delta_{\mathrm{ac}}$ & -1.9 \\
$\Delta_{\mathrm{ee}}$ & 4.7 & $\Delta_{\mathrm{ad}}$ & -1.7 \\
$\Delta_{\mathrm{ff}}$ & 4.6 & $\Delta_{\mathrm{bc}}$ & -2.0 \\
$\Delta_{\mathrm{aa}}$ & 12.3 & $\Delta_{\mathrm{bd}}$ & -2.2 \\
$\Delta_{\mathrm{bb}}$ & 4.6 & & \\
$\Delta_{\mathrm{cc}}$ & 22.9 & & \\
$\Delta_{\mathrm{dd}}$ & 2.1 & &
\end{tabular}

fundamental and doubly excited states. The indices $a$ and $b$ denote the antisymmetric and symmetric stretching vibrations of the $\mathrm{C}=\mathrm{O}$ group (amide $\mathrm{I}$ ), $c$ and $d$ denote the antisymmetric and symmetric stretching vibrations of the $\mathrm{N}-\mathrm{H}$ group (amide A), and $e$ and $f$ denote the symmetric and antisymmetric stretching vibrations of the $\mathrm{C}-\mathrm{N}$ group (amide II). The parameters $\tilde{\omega}_{k}, \Omega_{j}, \Delta_{i i}$, and $\Delta_{i j}$ denote the intrinsic frequencies of the local modes, the transition energies for the one exciton states, and the diagonal and off-diagonal anharmonicities of the two-exciton states, respectively.

The low-resolution linear IR spectrum calculated using the eigenstates and transition dipole moments of the six-mode exciton Hamiltonian in the $1000-8000 \mathrm{~cm}^{-1}$ range is shown in Figure 1 together with an energy level scheme for all oneand two-exciton as well as some relevant three-exciton states, for a total of 139 states. A homogeneous line width of $\Gamma=5$ $\mathrm{cm}^{-1}$ (eq 5) has been assumed.

The fundamental transition frequencies obtained from the diagonalized exciton Hamiltonian are compared in Table 4 to the harmonic normal-mode frequencies and with experiment. ${ }^{43}$ The transition frequencies obtained from the exciton Hamiltonian are considerably lower than the corresponding harmonic values, particularly for the $\mathrm{N}-\mathrm{H}$ and $\mathrm{C}=\mathrm{O}$ vibrations, because higher excitations introduce stabilizing effects. In addition, the band splittings calculated using the anharmonic exciton Hamil- 


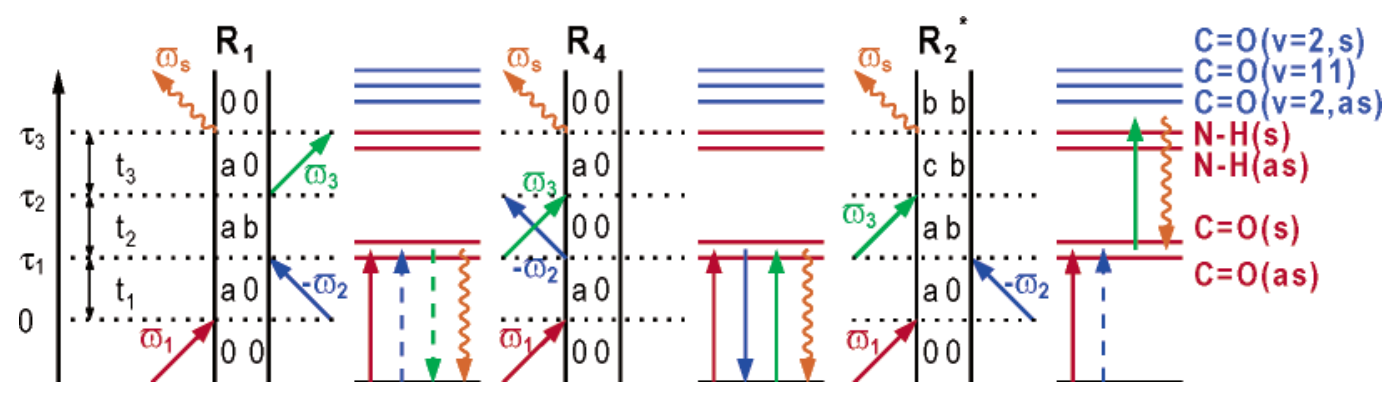

Figure 6. $\mathbf{k}_{\mathrm{II}}=+\mathbf{k}_{1}-\mathbf{k}_{2}+\mathbf{k}_{3}$ : Feynman diagrams $\left(\mathscr{R}_{\mathrm{s}}=\mathrm{R}_{1}+\mathrm{R}_{4}-\mathbf{R}_{2}^{*}\right)$ and energy level schemes for $\bar{\omega}_{1}=\bar{\omega}_{2}=\bar{\omega}_{3}=1770 \mathrm{~cm}^{-1}(\nu(\mathbf{C}=\mathrm{O}))$. $\mathrm{R}_{1}, \mathrm{R}_{4}$ : 4 pathways each. $\mathrm{R}_{2}^{*}$ : 20 pathways. Pulse width $= \pm 100 \mathrm{~cm}^{-1}$.
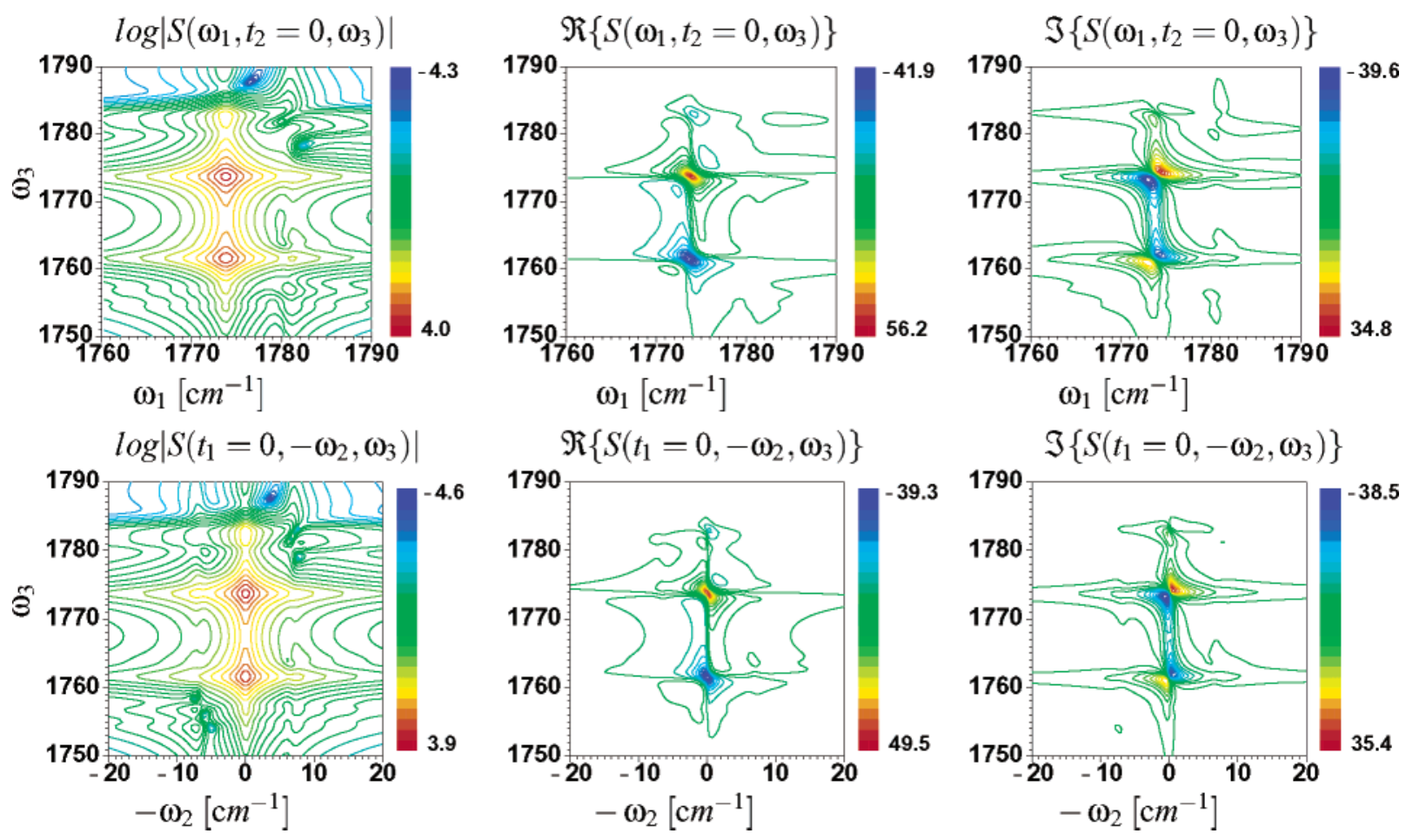

Figure 7. $\mathbf{k}_{\mathrm{II}}: 2 \mathrm{D}$ spectra $(z z z z)$ for $\bar{\omega}_{1}=\bar{\omega}_{2}=\bar{\omega}_{3}=1770 \mathrm{~cm}^{-1}(v(\mathrm{C}=\mathrm{O}))$. Upper panel: $t_{2}=0$. Lower panel: $t_{1}=0$.

TABLE 4: Calculated Normal Mode (B3LYP/6-31G(d,p)), Six-Mode Exciton Hamiltonian and Experimental Amide Bands $\left(\mathrm{cm}^{-1}\right.$, Unscaled)

\begin{tabular}{cccccl}
\hline $\begin{array}{c}\text { amide } \\
\text { band }\end{array}$ & eigenstate & $\begin{array}{c}\text { normal } \\
\text { mode }\end{array}$ & $\begin{array}{c}\text { exciton } \\
\text { Hamiltonian }\end{array}$ & $\operatorname{exptl}^{a}$ & description \\
\hline III & $\Omega_{\mathrm{e}}$ & $1450^{b}$ & 1420 & $d$ & $v_{\mathrm{s}}(\mathrm{C}-\mathrm{N})$ \\
III & $\Omega_{\mathrm{f}}$ & $1433^{b}$ & 1442 & $d$ & $v_{\mathrm{as}}(\mathrm{C}-\mathrm{N})$ \\
I & $\Omega_{\mathrm{a}}$ & $1831^{b, c}$ & 1774 & $\approx 1720$ & $v_{\mathrm{as}}(\mathrm{C}=\mathrm{O})$ \\
I & $\Omega_{\mathrm{b}}$ & $1831^{b, c}$ & 1781 & $\approx 1720$ & $v_{\mathrm{s}}(\mathrm{C}=\mathrm{O})$ \\
A & $\Omega_{\mathrm{c}}$ & 3643 & 3459 & $\approx 3150^{e}$ & $v_{\mathrm{as}}(\mathrm{N}-\mathrm{H})$ \\
A & $\Omega_{\mathrm{d}}$ & 3644 & 3463 & $\approx 3150^{e}$ & $v_{\mathrm{s}}(\mathrm{N}-\mathrm{H})$
\end{tabular}

${ }^{a}$ In DMSO. ${ }^{43}{ }^{b} \delta(\mathrm{N}-\mathrm{H})$ vibrations contribute to this normal mode. ${ }^{c} \delta(\mathrm{C}-\mathrm{H})$ vibrations contribute to this normal mode. ${ }^{d}$ Not assigned. ${ }^{e}$ Broad band.

tonian are larger than those of the normal modes in which the symmetric and antisymmetric combinations of the $\mathrm{N}-\mathrm{H}$ and $\mathrm{C}=\mathrm{O}$ vibrations are nearly degenerate. The experimental $\mathrm{N}-\mathrm{H}$ stretching band (amide A) in DMSO as well as in $\mathrm{KBr}$ is sufficiently broad that two individual bands are not resolved. ${ }^{43}$ Also, the band maximum is still considerably red-shifted compared to the exciton Hamiltonian. The agreement of the exciton Hamiltonian band positions for the $\mathrm{C}=\mathrm{O}$ vibrations with experiment is much better, although the splitting is overestimated compared to the experimental spectrum in DMSO. ${ }^{43}$ Overtones and combination bands of the $\mathrm{C}-\mathrm{N}$ stretching vibrations, which significantly contribute to the amide II bands, absorb at 2836 , 2859, and $2879 \mathrm{~cm}^{-1}$. This is about $600 \mathrm{~cm}^{-1}$ lower than the fundamental $\mathrm{N}-\mathrm{H}$ frequencies. Thus, a Fermi resonance splitting between them is missed, although the modes mutually contribute to the eigenvectors, but only marginally.

\section{Survey of Third-Order 2D IR Spectra}

In this section, we present one- and two-color simulations of all possible three-pulse techniques using the simplest $z z z z$ polarization. Other polarizations will be discussed in the next section.

A. $\mathbf{k}_{\mathbf{I}}=-\mathbf{k}_{\mathbf{1}}+\mathbf{k}_{\mathbf{2}}+\mathbf{k}_{\mathbf{3}}$. One-Color Simulations. Figure 2 shows all possible Liouville space pathways depicted as doublesided Feynman diagrams for $\mathbf{k}_{\mathrm{I}}$ within the RWA. The corresponding energy level schemes are shown to the right of the respective diagrams. (A rectangular bandwidth of $200 \mathrm{~cm}^{-1}$ is assumed for each of the three interacting pulses; that is, all energy levels within $\bar{\omega}_{\mathrm{n}} \pm 200 / 2 \mathrm{~cm}^{-1}$ are considered to be resonant with the carrier frequency $\bar{\omega}_{n}$ ). For a one-color experiment where $\bar{\omega}_{1}=\bar{\omega}_{2}=\bar{\omega}_{3}=1770 \mathrm{~cm}^{-1}$ are resonant with the symmetric and antisymmetric $\mathrm{C}=\mathrm{O}$ stretching modes, 


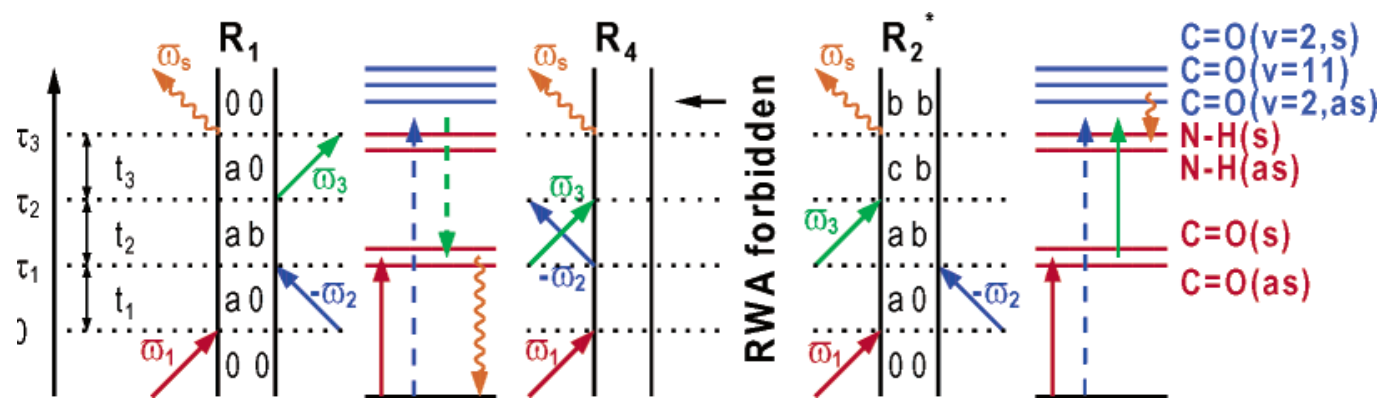

Figure 8. $\mathbf{k}_{\mathrm{II}}=+\mathbf{k}_{1}-\mathbf{k}_{2}+\mathbf{k}_{3}$ : Feynman diagrams $\left(\mathscr{R}_{\mathrm{S}}=\mathrm{R}_{1}+\mathrm{R}_{4}-\mathrm{R}_{2}^{*}\right)$ and energy level schemes for $\bar{\omega}_{1}=\bar{\omega}_{3}=1770 \mathrm{~cm}^{-1}(\nu(\mathrm{C}=\mathrm{O}))$, $\bar{\omega}_{2}=3461 \mathrm{~cm}^{-1}(v(\mathrm{~N}-\mathrm{H})) . \mathrm{R}_{1}: 20$ pathways. $\mathrm{R}_{2}^{*}: 50$ pathways. Pulse width $= \pm 100 \mathrm{~cm}^{-1}$.
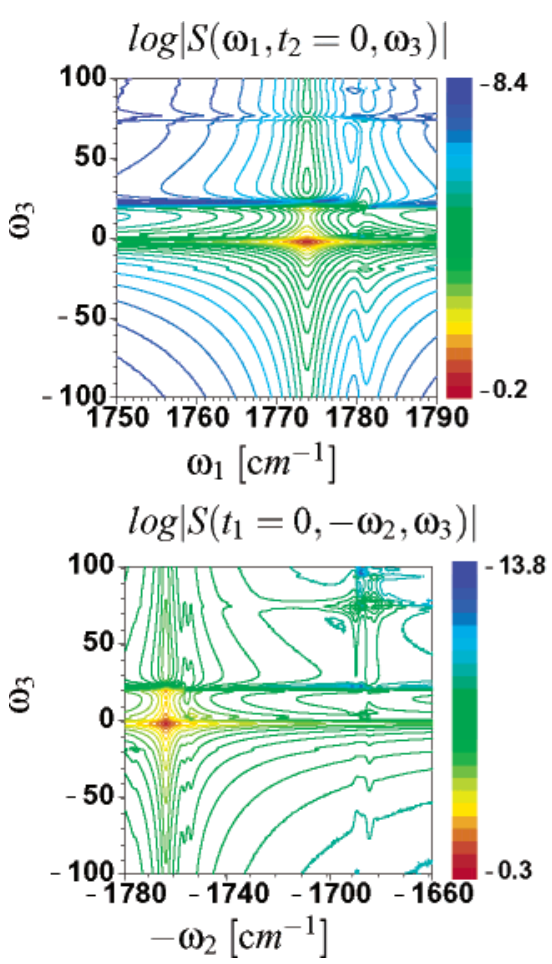

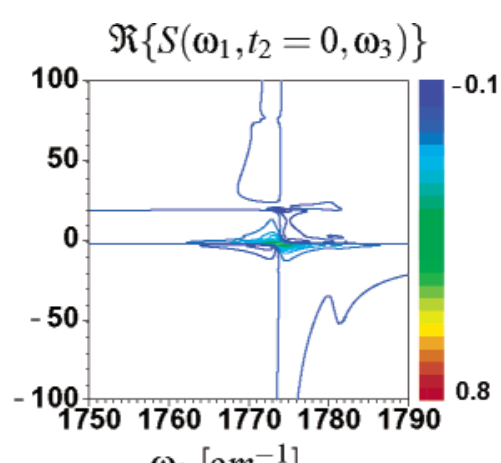

$\omega_{1}\left[\mathrm{~cm}^{-1}\right]$

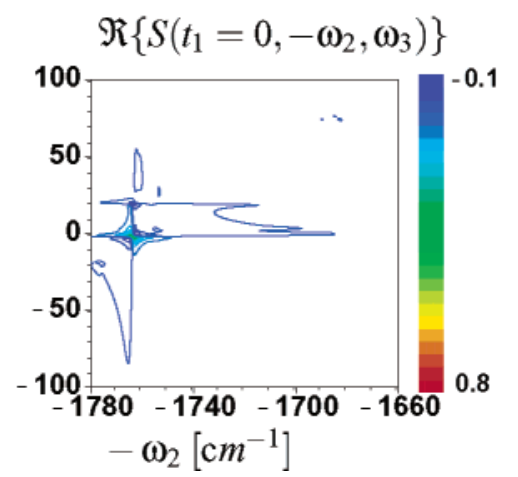

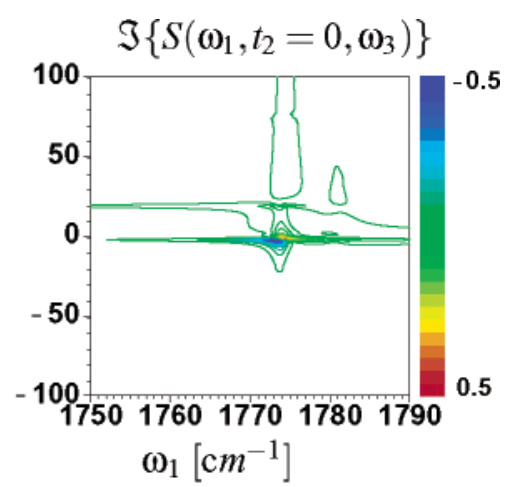

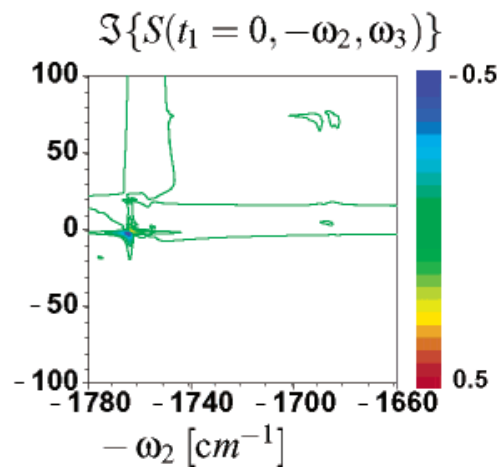

Figure 9. $\mathbf{k}_{\mathrm{II}}: 2 \mathrm{D} \operatorname{spectra}(z z z z)$ for $\bar{\omega}_{1}=\bar{\omega}_{3}=1770 \mathrm{~cm}^{-1}(v(\mathrm{C}=\mathrm{O})), \bar{\omega}_{2}=3461 \mathrm{~cm}^{-1}(v(\mathrm{~N}-\mathrm{H}))$. Upper panel: $t_{2}=0$. Lower panel: $t_{1}=0$.

this results in a total number of 4 terms each for $\mathrm{R}_{2}$ and $\mathrm{R}_{3}$ and 20 terms for $\mathrm{R}_{1}^{*}$. 2D IR spectra are calculated for $t_{1}=0$ as well as $t_{2}=0$ and displayed in the frequency domain as a function of $-\omega_{1}$ and $\omega_{3}$ or $\omega_{2}$ and $\omega_{3}$, respectively (Figure 3); logarithmic magnitude and real and imaginary signals are shown here and in all subsequent spectral figures from left to right.

Along the $-\omega_{1}$ axis, we see the two $v(\mathrm{C}=\mathrm{O})$ resonances of 1773.6 and $1780.8 \mathrm{~cm}^{-1}$ (Table 3 ). Resonances corresponding to the energy difference between the states populated by $\bar{\omega}_{2}$ and $\bar{\omega}_{3}\left(\mathrm{R}_{2}, \mathrm{R}_{3}\right)$ and $\bar{\omega}_{1}$ and $\bar{\omega}_{3}\left(\mathrm{R}_{1}^{*}\right)$, respectively, appear along the $\omega_{3}$ axis. For $R_{2}$ and $R_{3}$ these resonances include the diagonal peaks $\left(-\Omega_{\mathrm{a}}, \Omega_{\mathrm{a}}\right)$ and $\left(-\Omega_{\mathrm{b}}, \Omega_{\mathrm{b}}\right)$ as well as the cross-peaks of the $v(\mathrm{C}=\mathrm{O})$ modes $\left(-\Omega_{\mathrm{a}}, \Omega_{\mathrm{b}}\right)$ and $\left(-\Omega_{\mathrm{b}}, \Omega_{\mathrm{a}}\right)$ representing their anharmonic coupling (cf. Table 2 for notation). $\mathrm{R}_{1}^{*}$ contributes off-diagonal resonances with the $v(\mathrm{C}=\mathrm{O})$ overtones $\left(-\Omega_{\mathrm{a}}\right.$, $\left.\Omega_{\mathrm{a}}-\Delta_{\mathrm{aa}}\right),\left(-\Omega_{\mathrm{a}}, 2 \Omega_{\mathrm{b}}-\Delta_{\mathrm{bb}}-\Omega_{\mathrm{a}}\right)$ and $\left(-\Omega_{\mathrm{b}}, \Omega_{\mathrm{b}}-\Delta_{\mathrm{bb}}\right)$, $\left(-\Omega_{\mathrm{b}}, 2 \Omega_{\mathrm{a}}-\Delta_{\mathrm{aa}}-\Omega_{\mathrm{b}}\right)$, respectively, as well as with the combination modes $\left(-\Omega_{\mathrm{a}}, \Omega_{\mathrm{b}}-\Delta_{\mathrm{ab}}\right)$ and $\left(-\Omega_{\mathrm{b}}, \Omega_{\mathrm{a}}-\Delta_{\mathrm{ab}}\right)$. In addition, cross-peaks between $v(\mathrm{C}=\mathrm{O})$ and the fundamental $\mathrm{N}-\mathrm{H}$ stretching modes result from $\mathrm{R}_{1}^{*}$ pathways $\left[\left(-\Omega_{\mathrm{a}}, \Omega_{\mathrm{c}}-\right.\right.$ $\left.\Omega_{\mathrm{a}}\right),\left(-\Omega_{\mathrm{b}}, \Omega_{\mathrm{c}}-\Omega_{\mathrm{b}}\right)$, and $\left.\left(-\Omega_{\mathrm{a}}, \Omega_{\mathrm{d}}-\Omega_{\mathrm{a}}\right),\left(-\Omega_{\mathrm{b}}, \Omega_{\mathrm{d}}-\Omega_{\mathrm{b}}\right)\right]$. These would show up between 1678.1 and $1689.8 \mathrm{~cm}^{-1}$ on the $\omega_{3}$ axis, but their coupling is very weak and the resulting transition dipole moments are several orders of magnitude smaller than those for couplings within the $\mathrm{C}=\mathrm{O}$ manifold. Thus, this frequency range is excluded from the plots in Figure 3 . However, analysis of $\mathrm{C}=\mathrm{O} / \mathrm{N}-\mathrm{H}$ coupling is readily accessible in two-color experiments, as will be shown below.

This simulation corresponds to a two-pulse photon echo experiment, where the first pulse creates a coherence, and after the delay $t_{1}$, a pulse pair interrupts the coherence evolution and generates a set of Bohr frequencies from the transferred coherence. This scheme is analogous to the NMR 2D COSY pulse sequence. If $t_{2}$ is finite, coherence and population transfer occurs during $t_{2}$. This three-pulse stimulated photon echo experiment corresponds to the NMR 2D NOESY or stimulated spin-echo methods. Both IR techniques, named IRCOSY and three infrared pulse stimulated echo spectroscopy (THIRSTY), have already been applied in studies of small peptides. ${ }^{13,22,23,25,28,31,32,63}$

Setting $t_{1}=0$ corresponds to a transient grating pulse configuration, where a pulse pair $-\mathbf{k}_{1}+\mathbf{k}_{2}$ creates a grating from which the third pulse is scattered after a delay $t_{2}$. The calculated spectra show identical resonances in the $\omega_{3}$ axis, but now correlated to peaks appearing on the $\omega_{2}$ axis (Figure 3, lower panel). After the action of the pulse pair (during $t_{2}$ ) the 

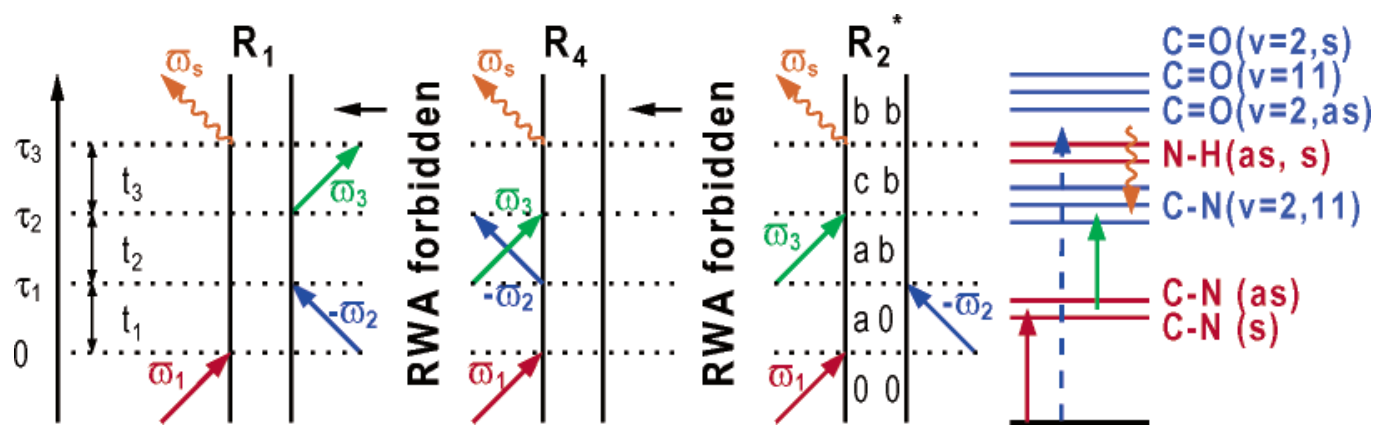

Figure 10. $\mathbf{k}_{\mathrm{II}}=+\mathbf{k}_{1}-\mathbf{k}_{2}+\mathbf{k}_{3}$ : Feynman diagrams $\left(\mathscr{R}_{\mathrm{s}}=\mathrm{R}_{1}+\mathrm{R}_{4}-\mathrm{R}_{2}^{*}\right)$ and energy level schemes for $\bar{\omega}_{1}=\bar{\omega}_{3}=1431 \mathrm{~cm}{ }^{-1}(\nu(\mathrm{C}-\mathrm{N}))$, $\bar{\omega}_{2}=3461 \mathrm{~cm}^{-1}(v(\mathrm{~N}-\mathrm{H}))$. $\mathrm{R}_{2}^{*}: 30$ pathways. Pulse width $= \pm 100 \mathrm{~cm}^{-1}$.
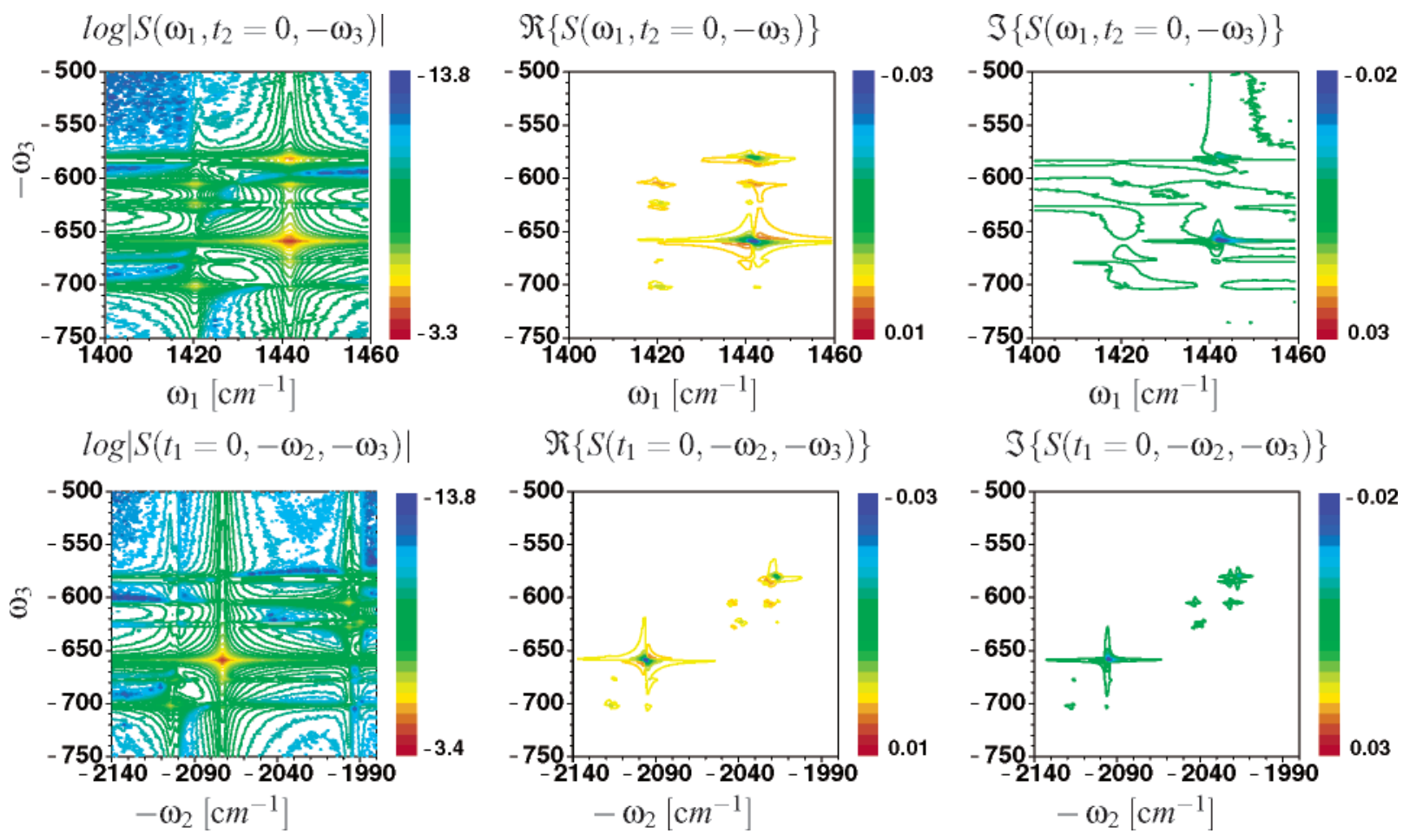

Figure 11. $\mathbf{k}_{\mathrm{II}}: 2 \mathrm{D} \operatorname{spectra}(z z z z)$ for $\bar{\omega}_{1}=\bar{\omega}_{3}=1431 \mathrm{~cm}^{-1}(\nu(\mathrm{C}-\mathrm{N})), \bar{\omega}_{2}=3461 \mathrm{~cm}^{-1}(\nu(\mathrm{N}-\mathrm{H}))$. Upper panel: $t_{2}=0$. Lower panel: $t_{1}=0$.

system is either in a population $\left(\omega_{2}=0\right)$ or a coherence between the symmetric and antisymmetric $v(\mathrm{C}=\mathrm{O})$ stretching vibrations $\left(\omega_{2}= \pm\left(\Omega_{\mathrm{a}}-\Omega_{\mathrm{b}}\right)\right)$ for $\mathrm{R}_{2}$ and $\mathrm{R}_{1}^{*}$ pathways. For $\mathrm{R}_{3}$ the system is back in the vibrational ground state. Thus, resonances in $\omega_{2}$ appear either at $0 \mathrm{~cm}^{-1}$ or at positive and negative energy level splittings between the $\mathrm{C}=\mathrm{O}$ modes. In $\omega_{3}$, peaks appear at $\left(0, \Omega_{\mathrm{a}}\right),\left(0, \Omega_{\mathrm{b}}\right),\left(\Omega_{\mathrm{b}}-\Omega_{\mathrm{a}}, \Omega_{\mathrm{a}}\right)$, and $\left(\Omega_{\mathrm{a}}-\Omega_{\mathrm{b}}, \Omega_{\mathrm{b}}\right)$ for $\mathrm{R}_{2}$ pathways and at $\left(0, \Omega_{\mathrm{a}}\right)$ and $\left(0, \Omega_{\mathrm{b}}\right)$ for $\mathrm{R}_{3}$ pathways. For $\mathrm{R}_{1}^{*}$, energy splittings between the $\mathrm{C}=\mathrm{O}$ overtones or $\mathrm{N}-\mathrm{H}$ stretching bands, respectively, and the $\mathrm{C}=\mathrm{O}$ fundamental transitions appear.

Two-Color Simulations. Feynman diagrams and energy level schemes are shown in Figure 4 for a two-color $\mathbf{k}_{\mathrm{I}}$ experiment with $\bar{\omega}_{1}=\bar{\omega}_{3}=1770 \mathrm{~cm}^{-1}$ tuned to the $v(\mathrm{C}=\mathrm{O})$ resonances and $\bar{\omega}_{2}=3461 \mathrm{~cm}^{-1}$ tuned to the $\mathrm{N}-\mathrm{H}$ stretching bands. For $\mathrm{R}_{2}$ and $\mathrm{R}_{1}^{*}$ the first two pulses excite $\mathrm{C}=\mathrm{O}$ fundamental and $\mathrm{N}-\mathrm{H}$ fundamental or $\mathrm{C}=\mathrm{O}$ two-exciton states, respectively. The third pulse leads either to deexcitation of the one exciton $\mathrm{C}=\mathrm{O}$ states $\left(\mathrm{R}_{2}\right)$ or excitation of $\mathrm{C}=\mathrm{O}$ three-exciton and $\mathrm{C}=\mathrm{O} / \mathrm{N}-\mathrm{H}$ two-exciton states $\left(\mathrm{R}_{1}^{*}\right) . \mathrm{R}_{3}$ pathways are forbidden within the RWA as the second pulse is nonresonant. Figure 5 displays two- color 2D IR photon echo spectra for $t_{2}=0$ (upper panel) and $t_{1}=0$ (lower panel). In $-\omega_{1}$ only $\mathrm{C}=\mathrm{O}$ one-exciton resonances appear just as in the one-color experiment. In $\omega_{3} R_{2}$ pathways contribute 10 two-exciton $\mathrm{C}=\mathrm{O}$ and $\mathrm{N}-\mathrm{H}$ one-exciton resonances. The $\mathrm{R}_{1}^{*}$ diagram leads to 80 terms showing the splitting between the $\mathrm{C}=\mathrm{O}$ three-exciton or $\mathrm{C}=\mathrm{O} / \mathrm{N}-\mathrm{H}$ two-exciton states, respectively, and $\mathrm{C}=\mathrm{O}$ fundamental bands. Cross-peaks showing the coupling between the $\mathrm{C}=\mathrm{O}$ and the $\mathrm{N}-\mathrm{H}$ modes are thus observed at $\left(\Omega_{\mathrm{a}}, \Omega_{\mathrm{c}}\right),\left(\Omega_{\mathrm{a}}, \Omega_{\mathrm{d}}\right),\left(\Omega_{\mathrm{b}}, \Omega_{\mathrm{c}}\right)$, and $\left(\Omega_{\mathrm{a}}, \Omega_{\mathrm{d}}\right)$. The $\omega_{2}$ axis shows splittings between the $\mathrm{C}=\mathrm{O}$ two-exciton or $\mathrm{N}-\mathrm{H}$ one-exciton states and the $\mathrm{C}=\mathrm{O}$ fundamentals. This corresponds to a two-color transient grating experiment.

B. $\mathbf{k}_{\mathrm{II}}=+\mathbf{k}_{\mathbf{1}}-\mathbf{k}_{\mathbf{2}}+\mathbf{k}_{\mathbf{3}}$. One-Color Simulations. Feynman diagrams for $\mathbf{k}_{\mathrm{II}}$ together with energy level schemes for $\bar{\omega}_{1}=$ $\bar{\omega}_{2}=\bar{\omega}_{3}=1770 \mathrm{~cm}^{-1}$ are shown in Figure 6. An assumed pulse bandwidth of $\pm 100 \mathrm{~cm}^{-1}$ selects 4 terms for $\mathrm{R}_{1}$ and $\mathrm{R}_{4}$ and to 20 for $\mathrm{R}_{2}^{*}$. Simulated $2 \mathrm{D}$ IR spectra are displayed in Figure 7.

For $t_{1}=0$, the $\mathbf{k}_{\mathrm{I}}$ and $\mathbf{k}_{\mathrm{II}}$ techniques are identical and are known as transient grating. For $t_{2}=0$ the order of the pulse 


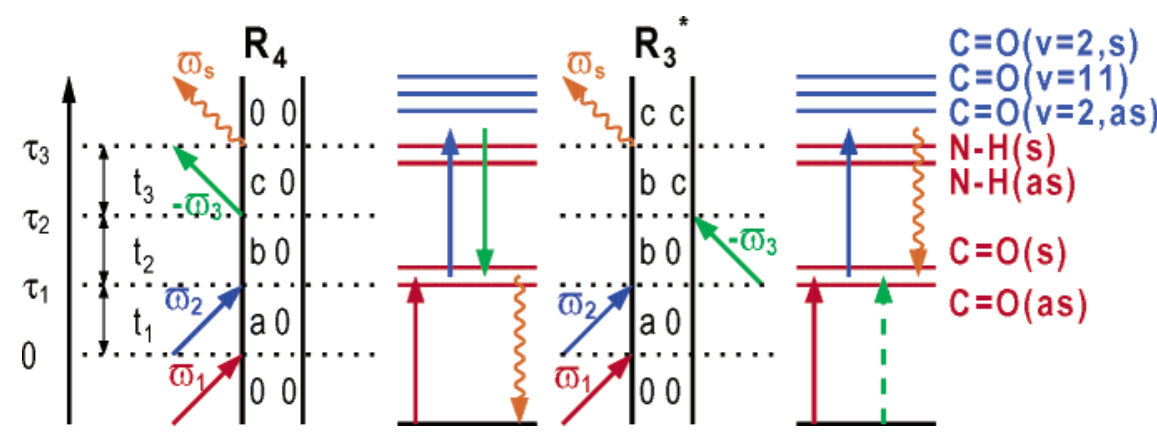

Figure 12. $\mathbf{k}_{\mathrm{III}}=+\mathbf{k}_{1}+\mathbf{k}_{2}-\mathbf{k}_{3}$ : Feynman diagrams $\left(\mathscr{R}_{\mathrm{s}}=\mathrm{R}_{4}-\mathrm{R}_{3}^{*}\right)$ and energy level schemes for $\bar{\omega}_{1}=\bar{\omega}_{2}=\bar{\omega}_{3}=1770 \mathrm{~cm}-1(\nu(\mathrm{C}=\mathrm{O}))$. $\mathbf{R}_{4}$ : 20 pathways. $R_{3}^{*}$ : 20 pathways. Pulse width $= \pm 100 \mathrm{~cm}^{-1}$.
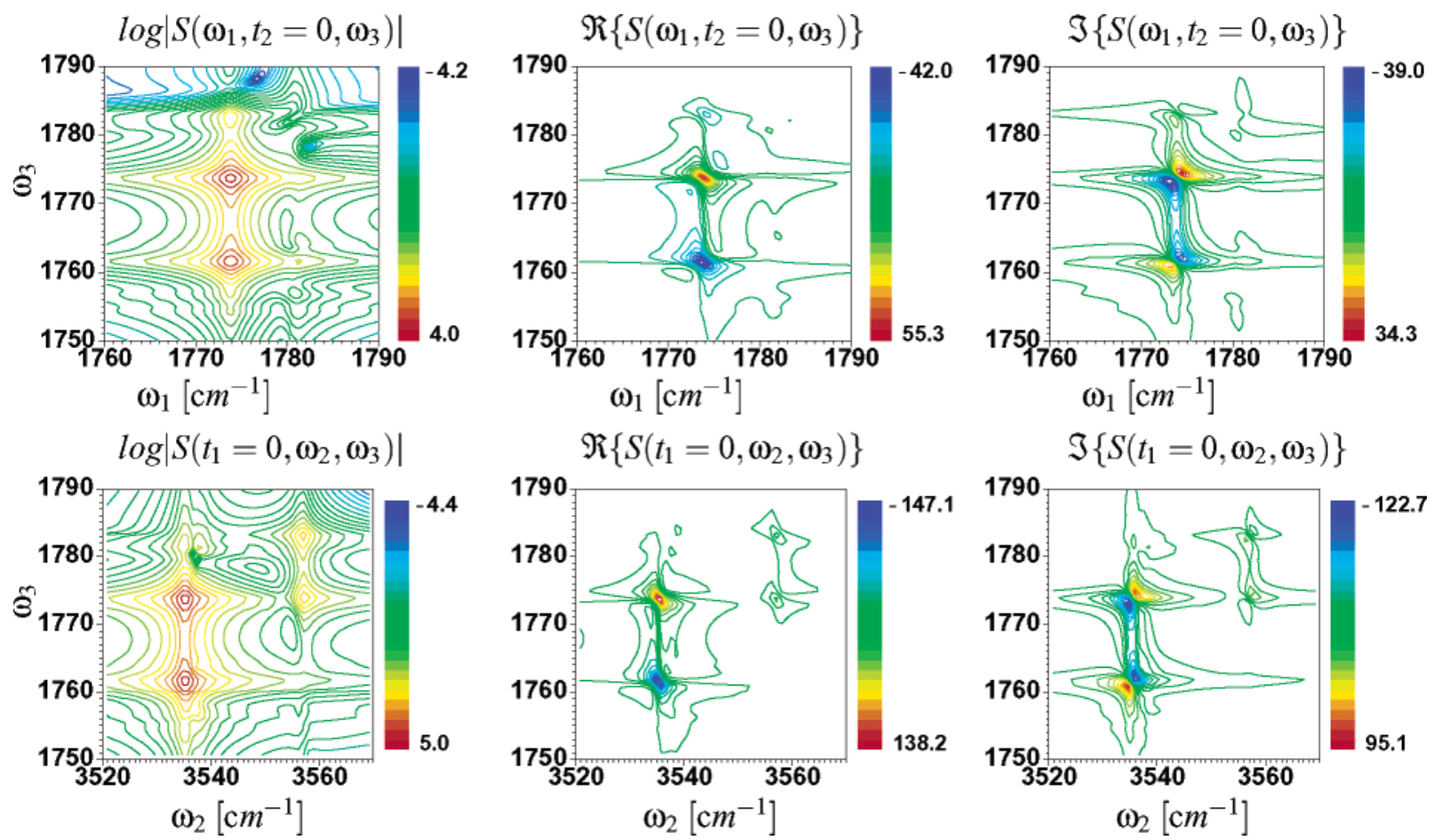

Figure 13. $\mathbf{k}_{\mathrm{III}}$ : 2D spectra $(z z z z)$ for $\bar{\omega}_{1}=\bar{\omega}_{2}=\bar{\omega}_{3}=1770 \mathrm{~cm}^{-1}(v(\mathrm{C}=\mathrm{O}))$. Upper panel: $t_{2}=0$. Lower panel: $t_{1}=0$.

pair $\left(\mathbf{k}_{1}-\mathbf{k}_{2}\right)$ and the single pulse are reversed defining a reversed transient grating experiment.

Two-Color Simulations. A two-color experiment is simulated for $\bar{\omega}_{1}=\bar{\omega}_{3}=1770 \mathrm{~cm}^{-1}$ and $\bar{\omega}_{2}=3461 \mathrm{~cm}^{-1}$. The $\mathrm{R}_{1}$ diagram contributes 20 terms, $\mathrm{R}_{4}$ is $\mathrm{RWA}$ forbidden and the $\mathrm{R}_{2}^{*}$ diagram gives 50 terms (Figure 8).

2D spectra are shown in Figure 9. On the $\omega_{2}$ axis the splitting between the $\mathrm{N}-\mathrm{H}$ fundamental or $\mathrm{C}=\mathrm{O}$ two-exciton states, respectively, and the $\mathrm{C}=\mathrm{O}$ one-exciton states is seen. During $t_{3} \mathrm{R}_{1}$ generates either a population state of the $\mathrm{C}=\mathrm{O}$ fundamental or a coherence between them, and thus, resonances on the $\omega_{3}$ axis appear at $0 \mathrm{~cm}^{-1}$ or $\left(\Omega_{\mathrm{a}}-\Omega_{\mathrm{b}}\right)$. $\mathrm{R}_{2}^{*}$ leads to populations or coherences of the $\mathrm{N}-\mathrm{H}$ fundamental and the $\mathrm{C}=\mathrm{O}$ two-exciton states so that the $\omega_{3}$ axis displays the respective splittings.

We next propose a two-color experiment designed to probe a potential Fermi resonance between the overtones of the amide II modes. This is approximately described by the $\mathrm{C}-\mathrm{N}$ twoexciton states, and the $\mathrm{N}-\mathrm{H}$ fundamental transitions. At the same time, the coupling between overtones of the amide I mode, the $\mathrm{C}=\mathrm{O}$ two-exciton states, and the $\mathrm{N}-\mathrm{H}$ one-exciton states will be included. We propose to tune the $\bar{\omega}_{1}$ and $\bar{\omega}_{3}$ pulses to the $\mathrm{C}-\mathrm{N}$ fundamental transition (amide II) and to adjust $\bar{\omega}_{2}$ to the $\mathrm{N}-\mathrm{H}$ one-exciton frequencies (amides $\mathrm{A}$ and $\mathrm{B}$ ). The corresponding Feynman diagram is shown in Figure 10. Only $\mathrm{R}_{2}^{*}$ Liouville space pathways survive, whereas $\mathrm{R}_{1}$ and $\mathrm{R}_{4}$ diagrams are forbidden within the RWA. 2D IR spectra for this two-color $\mathbf{k}_{\text {II }}$ technique are shown in Figure 11.

The $R_{2}^{*}$ Feynman diagram (Figure 10) shows that during $t_{3}$ the system evolves with frequencies corresponding to the energy splittings between the $\mathrm{N}-\mathrm{H}$ fundamental (amides $\mathrm{A}$ and $\mathrm{B}$ ) or $\mathrm{C}=\mathrm{O}$ (amide I) two-exciton states, respectively, and the $\mathrm{C}-\mathrm{N}$ (amide II) overtones and combination bands, which thus appear as resonances on the $-\omega_{3}$ axis. The $2 \mathrm{D}$ spectra plotted versus $\omega_{1}$ show the coupling with $\mathrm{C}-\mathrm{N}$ fundamental excitation (Figure 11, upper panel), whereas those plotted versus $-\omega_{2}$ show resonances for the $\mathrm{N}-\mathrm{H}$ one-exciton and $\mathrm{C}=\mathrm{O}$ two-exciton state energy splittings with the $\mathrm{C}-\mathrm{N}$ fundamental energy levels (Figure 11, lower panel). With exception of the coupling between the $\mathrm{C}=\mathrm{O}$ two-exciton combination band and the $\mathrm{C}-\mathrm{N}$ two-exciton states, all other couplings are large enough to be seen in the spectra. Thus, resonances along the $-\omega_{3}$ axis should directly monitor Fermi resonance couplings.

C. $\mathbf{k}_{\text {III }}=+\mathbf{k}_{\mathbf{1}}+\mathbf{k}_{\mathbf{2}}-\mathbf{k}_{\mathbf{3}}$. One-Color Simulations. Only two Feynman diagrams contribute to $\mathbf{k}_{\mathrm{III}}$ (Figure 12). Setting $t_{2}=0$ 


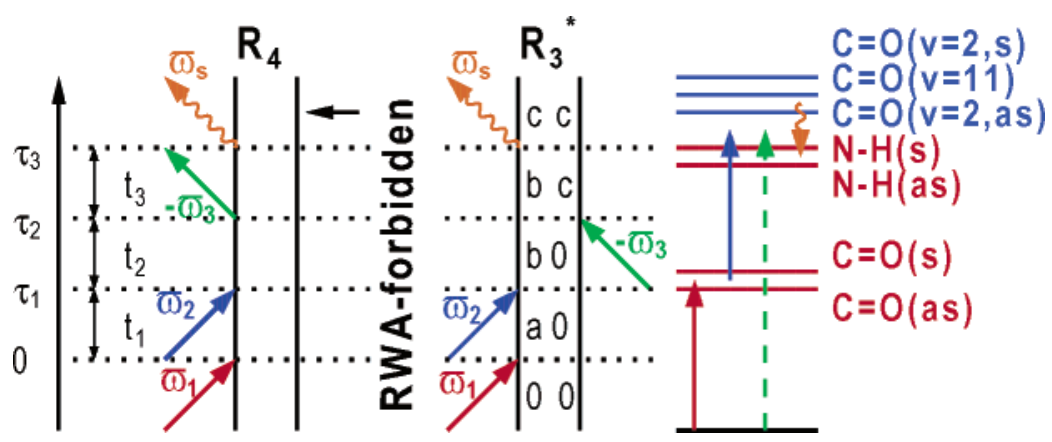

Figure 14. $\mathbf{k}_{\text {III }}=+\mathbf{k}_{1}+\mathbf{k}_{2}-\mathbf{k}_{3}$ : Feynman diagrams $\left(\mathscr{R}_{s}=\mathrm{R}_{4}-\mathrm{R}_{3}^{*}\right)$ and energy level schemes for $\bar{\omega}_{1}=\bar{\omega}_{2}=1770 \mathrm{~cm}^{-1}(v(\mathrm{C}=\mathrm{O})), \bar{\omega}_{3}=3461$ $\mathrm{cm}^{-1}(v(\mathrm{~N}-\mathrm{H})) . \mathrm{R}_{3}^{*}: 20$ pathways. Pulse width $= \pm 100 \mathrm{~cm}^{-1}$.
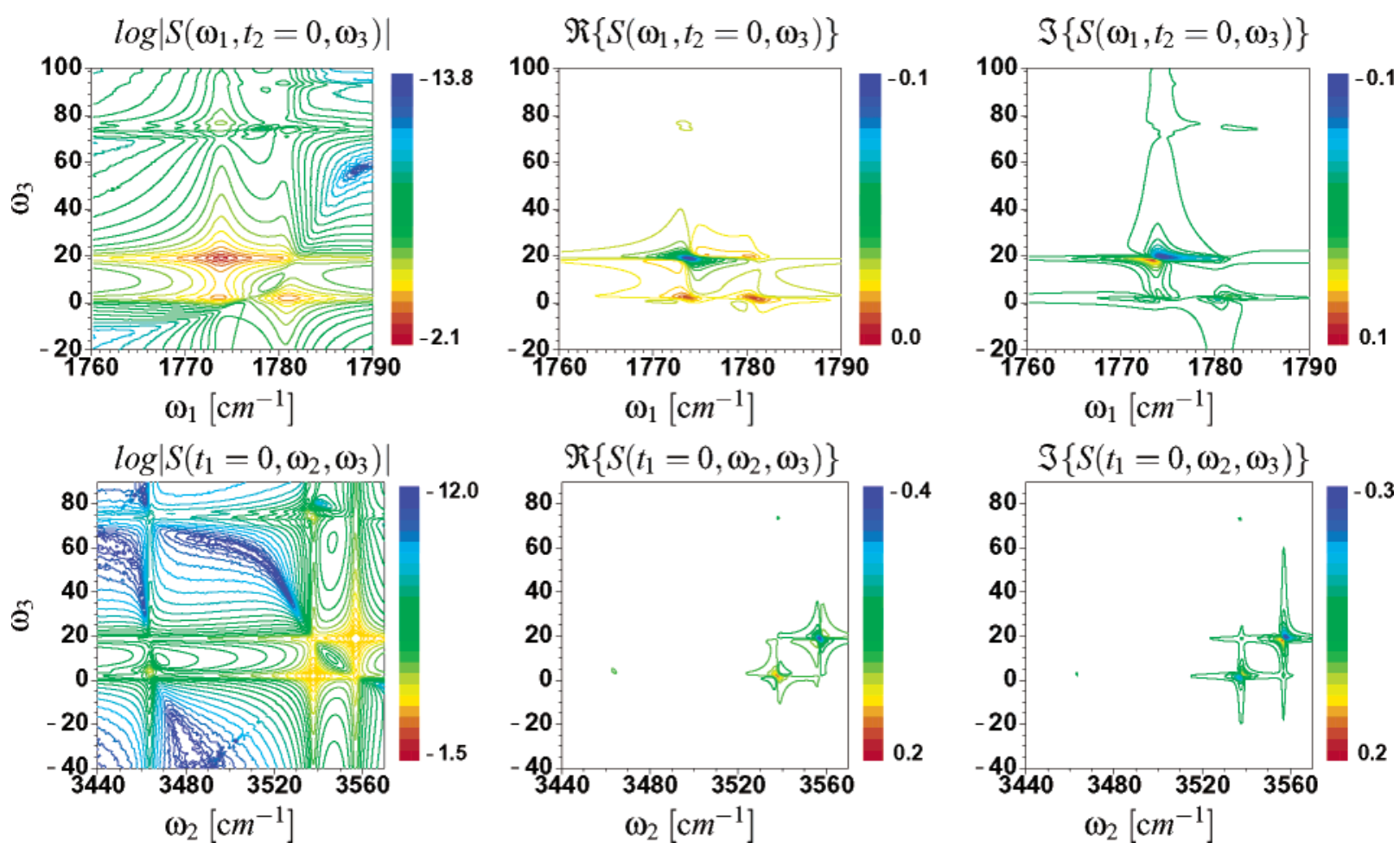

Figure 15. $\mathbf{k}_{\mathrm{III}}: 2 \mathrm{D}$ spectra $(z z z z)$ for $\bar{\omega}_{1}=\bar{\omega}_{2}=1770 \mathrm{~cm}^{-1}(v(\mathrm{C}=\mathrm{O})), \bar{\omega}_{3}=3461 \mathrm{~cm}^{-1}(v(\mathrm{~N}-\mathrm{H}))$. Upper panel: $t_{2}=0$. Lower panel: $t_{1}=0$.

defines a reversed transient grating experiment (Figure 13, upper panel), where a single pulse $\left(\mathbf{k}_{1}\right)$ comes first followed by a pulse pair $\left(\mathbf{k}_{2}-\mathbf{k}_{3}\right)$. For $t_{1}=0$ a reversed photon echo pulse configuration results (Figure 13, lower panel). For $\bar{\omega}_{1}=\bar{\omega}_{2}=$ $\bar{\omega}_{3}=1770 \mathrm{~cm}^{-1}$ the first two pulses $\left(\mathbf{k}_{1}+\mathbf{k}_{2}\right)$ generate a coherence of the vibrational ground state and the $\mathrm{C}=\mathrm{O}$ overtone and combination bands or the $\mathrm{N}-\mathrm{H}$ stretching bands. Thus, the corresponding energy levels appear as $\omega_{2}$ resonances. In $\omega_{3}$ the two $\mathrm{C}=\mathrm{O}$ resonances appear for $\mathrm{R}_{4}$ (20 terms totally), whereas $\mathrm{R}_{3}^{*}$ pathways (20 totally) lead to resonances corresponding to the splitting between the $\mathrm{C}=\mathrm{O}$ overtones or $\mathrm{N}-\mathrm{H}$ fundamentals, respectively, and the $\mathrm{C}=\mathrm{O}$ fundamental bands. Again, resonances involving the $\mathrm{N}-\mathrm{H}$ bands are rather weak and not shown.

Two-Color Simulations. In a $\mathbf{k}_{\text {III }}$ two-color experiment with $\bar{\omega}_{1}=\bar{\omega}_{2}=1770 \mathrm{~cm}^{-1}(\nu(\mathrm{C}=\mathrm{O}))$ and $\bar{\omega}_{3}=3461 \mathrm{~cm}^{-1}$ $(v(\mathrm{~N}-\mathrm{H}))$ the diagram $\mathrm{R}_{4}$ is forbidden within the RWA and all 20 terms originate from $R_{3}^{*}$ (Figure 14). The corresponding 2D spectra are shown in Figure 15. On the $\omega_{2}$ axis resonances corresponding to the $\mathrm{N}-\mathrm{H}$ fundamental and two-exciton $\mathrm{C}=\mathrm{O}$ energy levels appear. The splittings between those levels are seen on the $\omega_{3}$ axis.

D. $\mathbf{k}_{\mathbf{I V}}=+\mathbf{k}_{\mathbf{1}}+\mathbf{k}_{\mathbf{2}}+\mathbf{k}_{\mathbf{3}}$. One-Color Simulations. This sum frequency generation technique, which has not been reported yet using ultrafast infrared pulses, is particularly interesting because it is the only one that carries information on triply excited states. The signal, however, is expected to be much weaker than for the other techniques as a transition dipole moment for a three-quantum transition, which is usually rather small, is involved. Only a single Feynman diagram contributes to $\mathbf{k}_{\mathrm{IV}}$, as all interactions occur as absorption on the ket side (Figure 16). For $\bar{\omega}_{1}=\bar{\omega}_{2}=\bar{\omega}_{3}=1770 \mathrm{~cm}^{-1}$ three-exciton states $(\mathrm{C}=\mathrm{O}, v=3,21,12)$ as well as $\mathrm{C}=\mathrm{O} / \mathrm{N}-\mathrm{H}$ two-exciton bands are reached after the third pulse. These cannot be observed with any other one-color technique. The calculation involves a total number of 80 terms. 2D IR spectra with $\mathrm{C}=\mathrm{O}$ two-exciton states and $\mathrm{N}-\mathrm{H}$ fundamental bands as resonances in $\omega_{2}$ and resonances from the $\mathrm{C}=\mathrm{O}$ three-exciton and the $\mathrm{C}=\mathrm{O} / \mathrm{N}-\mathrm{H}$ combination bands in $\omega_{3}$ are shown in Figure 17.

Two-Color Simulations. The $\mathbf{k}_{\mathrm{IV}}$ two-color experiment with two $\mathrm{C}=\mathrm{O}$ and one $\mathrm{N}-\mathrm{H}$ excitation reaches higher excited states 


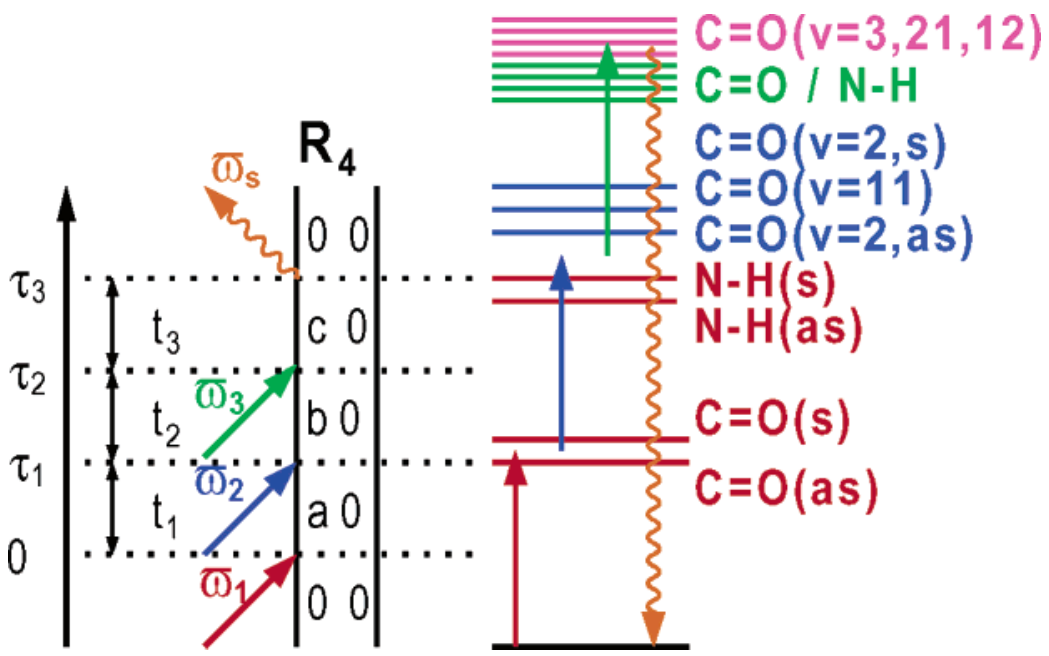

Figure 16. $\mathbf{k}_{\mathrm{IV}}=+\mathbf{k}_{1}+\mathbf{k}_{2}+\mathbf{k}_{3}$ : Feynman diagram $\left(\mathscr{R}_{\mathrm{s}}=\mathrm{R}_{4}\right)$ and energy level schemes for $\bar{\omega}_{1}=\bar{\omega}_{2}=\bar{\omega}_{3}=1770 \mathrm{~cm}^{-1}(v(\mathbf{C}=\mathrm{O}))$. $\mathbf{R}_{4}: 80$ pathways. Pulse width $= \pm 100 \mathrm{~cm}^{-1}$.
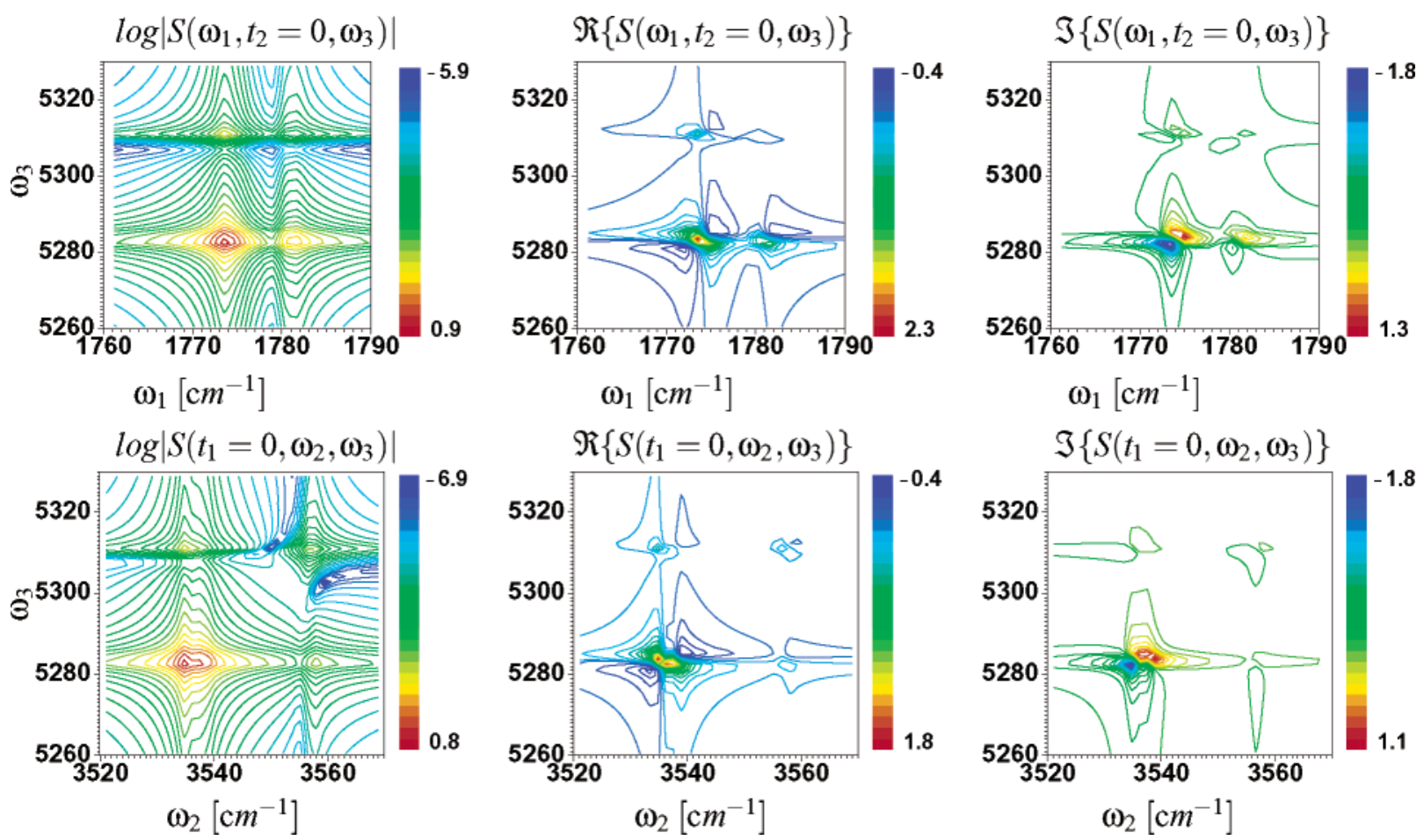

Figure 17. $\mathbf{k}_{\mathrm{IV}}$ : $2 \mathrm{D}$ spectra $(z z z z)$ for $\bar{\omega}_{1}=\bar{\omega}_{2}=\bar{\omega}_{3}=1770 \mathrm{~cm}^{-1}(\nu(\mathrm{C}=\mathrm{O}))$. Upper panel: $t_{2}=0$. Lower panel: $t_{1}=0$.

in the frequency range between 6895 and $7106 \mathrm{~cm}^{-1}$ (Figure 18). These correspond to the $\mathrm{N}-\mathrm{H}$ two-exciton states, combined $\mathrm{C}=\mathrm{O}$ three-exciton and $\mathrm{N}-\mathrm{H}$ states, and $\mathrm{C}=\mathrm{O}$ four-exciton states. They appear as resonances along the $\omega_{3}$ axis in $2 \mathrm{D}$ spectra plotted as a function of $\omega_{1}$ or $\omega_{2}$, respectively, and $\omega_{3}$ (Figure 19). The resonances along the $\omega_{2}$ axis originate from the $\mathrm{N}-\mathrm{H}$ fundamentals and the $\mathrm{C}=\mathrm{O}$ two-exciton states.

\section{Improving Resolution by Coherent Selectivity}

There are numerous possibilities for enhancing the selectivity and resolution of $n \mathrm{D}$ techniques that can be based on, for example, pulse shapes and phases. In this section, we present two examples.

A. Linear Combinations of the Basic Signals. Inspection of the combination of Feynman diagrams that give rise to the signals in different wavevector directions $\left(\mathbf{k}_{\mathrm{I}}-\mathbf{k}_{\mathrm{IV}}\right)$ shows that a system can evolve with the same frequencies in certain time intervals. Thus, they can share some of the resonances that are observed in frequency domain spectra. The peak intensities, however, may deviate, because of different Liouville space pathway couplings. Nevertheless, this suggests that linear combinations of heterodyne signals observed at different directions can eliminate or enhance certain peaks so that the spectra may be simplified or tuned to satisfy a specific goal. ${ }^{35,36}$ For example, cross-peaks may be better resolved if the diagonal peaks are minimized. In NMR, there is no directional selectivity because the radiowave wavelength is larger than the sample, $\mathbf{k}_{j}=0$, and all the terms that satisfy the RWA contribute in all directions. They can be distinguished, however, by their variations with the phase of the fields (each directional signal 


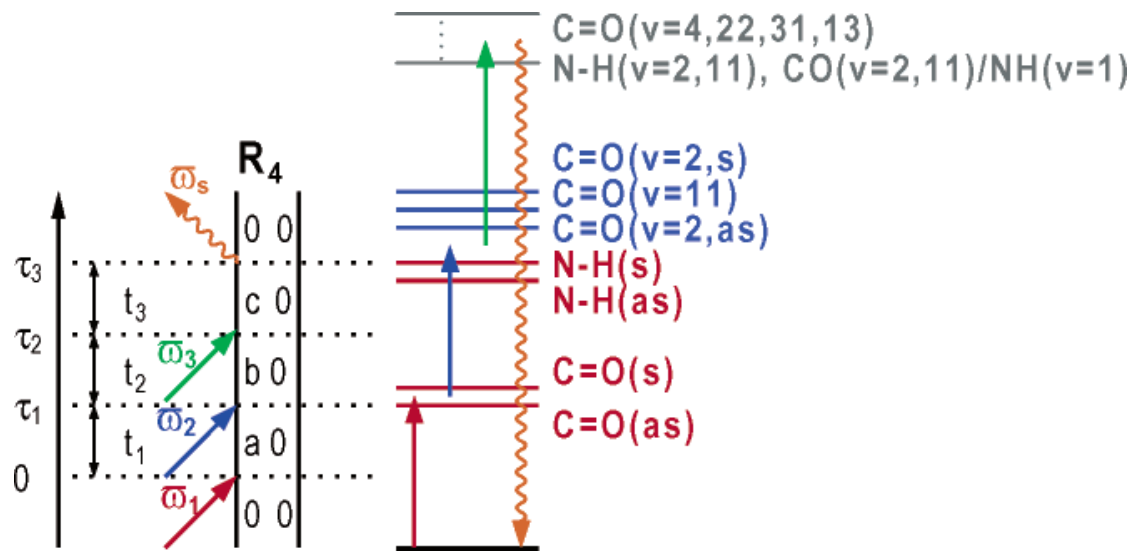

Figure 18. $\mathbf{k}_{\mathrm{IV}}=+\mathbf{k}_{1}+\mathbf{k}_{2}+\mathbf{k}_{3}$ : Feynman diagram $\left(\mathscr{R}_{s}=\mathrm{R}_{4}\right)$ and energy level schemes for $\bar{\omega}_{1}=\bar{\omega}_{2}=1770 \mathrm{~cm}^{-1}(\nu(\mathrm{C}=\mathrm{O})), \bar{\omega}_{3}=3461 \mathrm{~cm}-1$ $(v(\mathrm{~N}-\mathrm{H})) . \mathrm{R}_{4}: 120$ pathways. Pulse width $= \pm 100 \mathrm{~cm}^{-1}$.
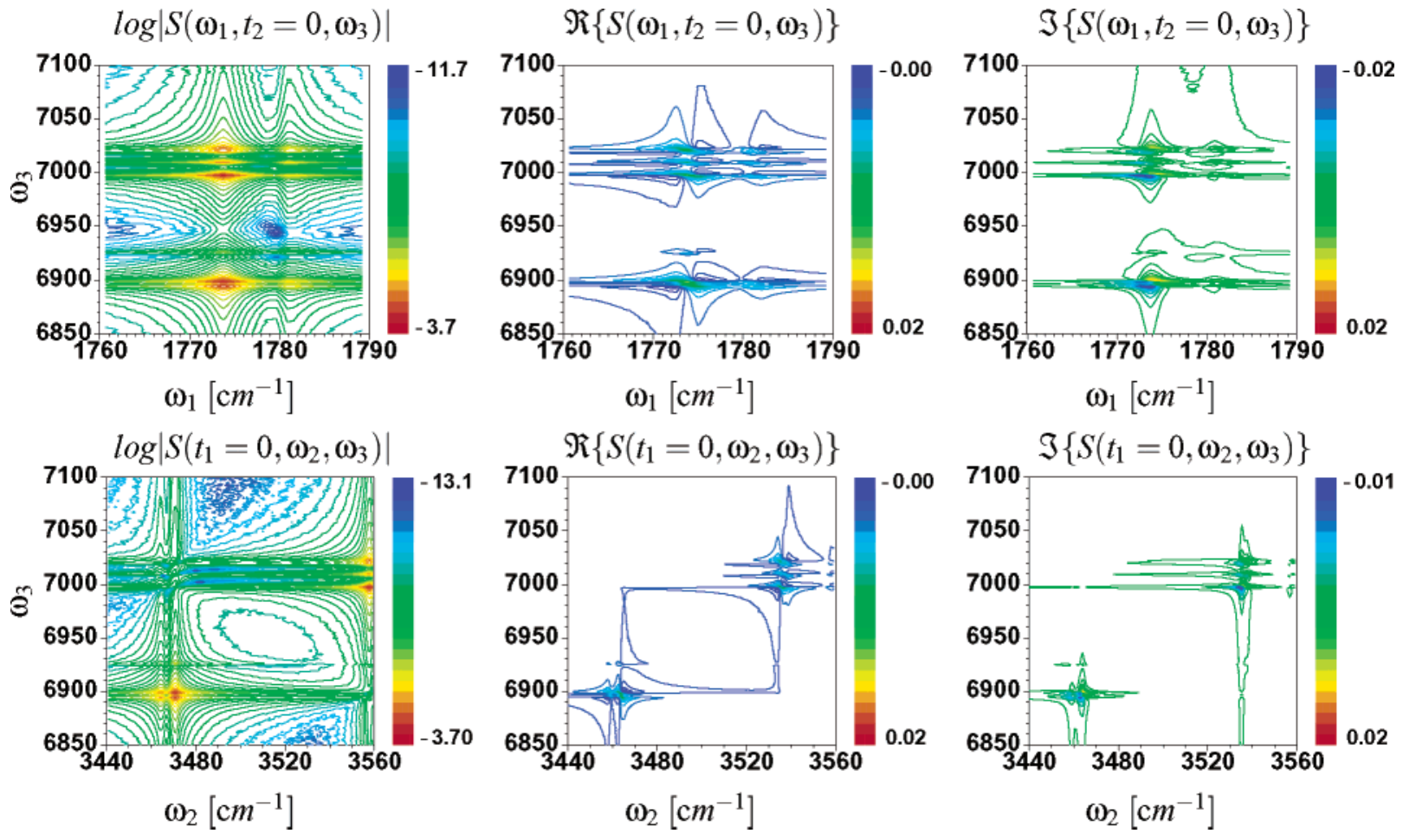

Figure 19. $\mathbf{k}_{\mathrm{IV}}$ : $2 \mathrm{D}$ spectra $(z z z z)$ for $\bar{\omega}_{1}=\bar{\omega}_{2}=1770 \mathrm{~cm}^{-1}(v(\mathrm{C}=\mathrm{O})), \bar{\omega}_{3}=3461 \mathrm{~cm}^{-1}(\nu(\mathrm{N}-\mathrm{H}))$. Upper panel: $t_{2}=0$. Lower panel: $t_{1}=0$.

has a characteristic phase signature). This is then used in phase cycling techniques to generate the combination of interest. In optical techniques the various heterodyne signals are separated spatially and may be combined to give the same information as in NMR phase cycling.

The $\mathbf{k}_{\mathrm{I}}, \mathbf{k}_{\text {II }}$, and $\mathbf{k}_{\text {III }}$ spectra all show four peaks corresponding to the two diagonal peaks $\left(\Omega_{\mathrm{a}}, \Omega_{\mathrm{a}}\right.$ and $\left.\Omega_{\mathrm{b}}, \Omega_{\mathrm{b}}\right)$ and the two off-diagonal peaks representing the coupling between the $\mathrm{C}=\mathrm{O}$ groups $\left(\Omega_{\mathrm{a}}, \Omega_{\mathrm{b}}\right.$ and $\left.\Omega_{\mathrm{b}}, \Omega_{\mathrm{a}}\right)$. The peak intensities depend on the wavevector directions. The $\mathbf{k}_{\mathrm{II}}$ and $\mathbf{k}_{\mathrm{III}}$ spectra exhibit 20 identical resonances and intensities for the couplings to the twoexciton $\mathrm{C}=\mathrm{O}$ and the one-exciton $\mathrm{N}-\mathrm{H}$ states. For $\mathbf{k}_{\mathrm{I}}$, however, two pathways add up to give the same resonance resulting in only 10 unique peaks. Thus, a linear combination $\mathbf{k}_{\mathrm{III}}-\mathbf{k}_{\mathrm{II}}$ (Figure 20) eliminates all peaks resulting from the Feynman diagrams $R_{2}^{*}\left(\mathbf{k}_{\mathrm{II}}\right)$ and $R_{3}^{*}\left(\mathbf{k}_{\mathrm{III}}\right)$ and the remaining diagonal peaks and cross-peaks change their relative intensities (Figure 21).
B. Polarization Configuration of Pulses. We now turn to discussing the role of specific polarization configurations in 2D spectra. ${ }^{23,26,47}$ The orientational part of the response function, eq $3 \mathrm{~b}$, is a fourth-rank tensor composed of 81 elements. For isotropic materials such as solutions of randomly oriented molecules, however, only four types of elements are nonzero, three of which are independent ${ }^{48}$ because they are related by

$$
\left\langle z_{v_{4}} z_{v_{3}} z_{v_{2}} z_{v_{1}}\right\rangle=\left\langle z_{v_{4}} z_{v_{3}} y_{v_{2}} y_{v_{1}}\right\rangle+\left\langle z_{v_{4}} y_{v_{3}} z_{v_{2}} y_{v_{1}}\right\rangle+\left\langle z_{v_{4}} y_{v_{3}} y_{v_{2}} z_{v_{1}}\right\rangle
$$

where $y$ and $z$ refer to polarizations of the four pulses in the laboratory frame, and $v_{1}, v_{2}, v_{3}, v_{4}$ are the four transition dipole moment vectors contributing to each Liouville space pathway. Expressions for three tensor elements were given in ref 26.

Angles between dipole derivatives calculated in the local internal coordinates basis with respect to each other and with 

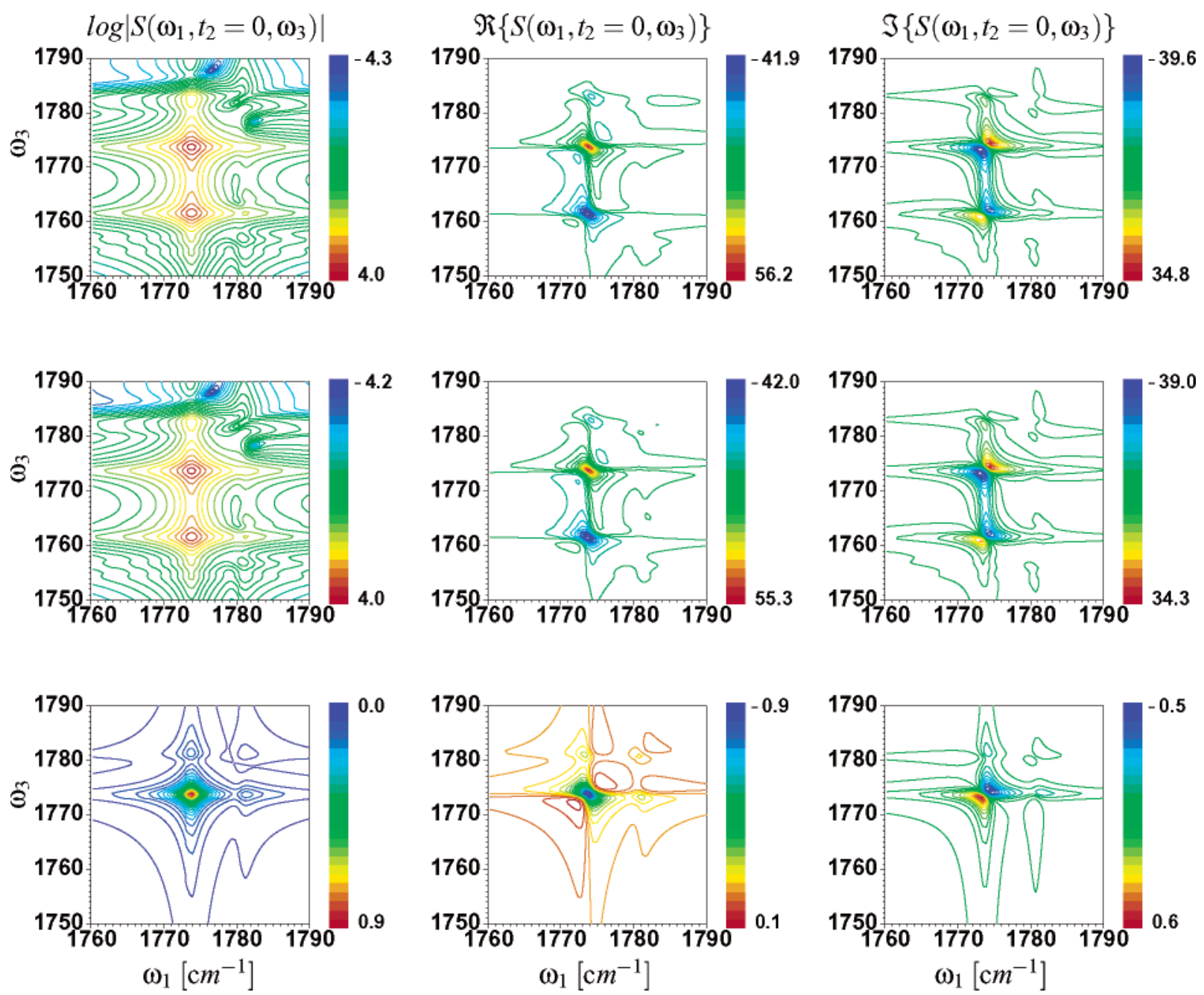

Figure 20. Linear combination of $2 \mathrm{D}$ spectra $(z z z z)$ for $\bar{\omega}_{1}=\bar{\omega}_{2}=\bar{\omega}_{3}=1777 \mathrm{~cm}^{-1}(v(\mathrm{C}=\mathrm{O}))$. Upper panel: $\mathbf{k}_{\mathrm{II}}$. Middle panel: $\mathbf{k}_{\mathrm{III}}$. Lower panel: $\mathbf{k}_{\text {III }}-\mathbf{k}_{\text {II }}$.

TABLE 5: Angles (deg) between Dipole Derivatives (Local Basis) and between Dipole Derivatives and Chemical Bonds

\begin{tabular}{|c|c|c|c|c|c|c|c|c|}
\hline dipole derivative & dipole derivative & angle & dipole derivative & dipole derivative & angle & dipole derivative & dipole derivative & angle \\
\hline $\mathrm{C}-\mathrm{N}(1)$ & $\mathrm{C}-\mathrm{N}(2)$ & 147.0 & $\mathrm{C}-\mathrm{N}(2)$ & $\mathrm{C}=\mathrm{O}(1)$ & 46.8 & $\mathrm{C}=\mathrm{O}(1)$ & $\mathrm{N}-\mathrm{H}(1)$ & 100.3 \\
\hline $\mathrm{C}-\mathrm{N}(1)$ & $\mathrm{C}=\mathrm{O}(1)$ & 155.7 & $\mathrm{C}-\mathrm{N}(2)$ & $\mathrm{C}=\mathrm{O}(2)$ & 155.7 & $\mathrm{C}=\mathrm{O}(1)$ & $\mathrm{N}-\mathrm{H}(2)$ & 100.8 \\
\hline $\mathrm{C}-\mathrm{N}(1)$ & $\mathrm{C}=\mathrm{O}(2)$ & 46.8 & $\mathrm{C}-\mathrm{N}(2)$ & $\mathrm{N}-\mathrm{H}(1)$ & 60.5 & $\mathrm{C}=\mathrm{O}(2)$ & $\mathrm{N}-\mathrm{H}(1)$ & 100.8 \\
\hline $\mathrm{C}-\mathrm{N}(1)$ & $\mathrm{N}-\mathrm{H}(1)$ & 103.4 & $\mathrm{C}-\mathrm{N}(2)$ & $\mathrm{N}-\mathrm{H}(2)$ & 103.4 & $\mathrm{C}=\mathrm{O}(2)$ & $\mathrm{N}-\mathrm{H}(2)$ & 100.3 \\
\hline $\mathrm{C}-\mathrm{N}(1)$ & $\mathrm{N}-\mathrm{H}(1)$ & 60.5 & $\mathrm{C}=\mathrm{O}(1)$ & $\mathrm{C}=\mathrm{O}(2)$ & 133.1 & $\mathrm{~N}-\mathrm{H}(1)$ & $\mathrm{N}-\mathrm{H}(2)$ & 125.3 \\
\hline dipole derivative & bond & angle & dipole derivative & bond & angle & dipole derivative & bond & angle \\
\hline $\mathrm{C}-\mathrm{N}$ & $\mathrm{C}-\mathrm{N}$ & 154.4 & $\mathrm{C}=\mathrm{O}$ & $\mathrm{C}=\mathrm{O}$ & 175.7 & $\mathrm{~N}-\mathrm{H}$ & $\mathrm{N}-\mathrm{H}$ & 9.2 \\
\hline $\mathrm{C}-\mathrm{N}$ & $\mathrm{C}=\mathrm{O}$ & 28.6 & $\mathrm{C}=\mathrm{O}$ & $\mathrm{C}-\mathrm{N}$ & 49.6 & $\mathrm{~N}-\mathrm{H}$ & $\mathrm{C}-\mathrm{N}$ & 129.0 \\
\hline
\end{tabular}

respect to the corresponding chemical bonds are given in Table 5. The $\mathrm{C}-\mathrm{N}$ and $\mathrm{C}=\mathrm{O}$ dipole derivatives point toward the carbon atoms of the respective bonds, and the $\mathrm{N}-\mathrm{H}$ dipole derivative points to the hydrogen atom of the $\mathrm{N}-\mathrm{H}$ bond. The $\mathrm{C}-\mathrm{N}$ dipole derivatives reside nearly in the $\mathrm{O}=\mathrm{C}-\mathrm{N}-\mathrm{H}$ plane $\left(0.8^{\circ}\right)$, whereas the $\mathrm{N}-\mathrm{H}\left(9.6^{\circ}\right)$ and $\mathrm{C}=\mathrm{O}\left(19.2^{\circ}\right)$ dipole derivative deviate appreciably from the peptide bond plane. Table 6 compiles angles between transition dipole moments in the eigenstate basis that are involved in the calculation of $\mathbf{k}_{\mathrm{I}}$ one-color $(v(\mathrm{C}=\mathrm{O}))$ spectra. The left four columns contain the four four states $(a-d)$ that contribute to a single Liouville space pathway. The corresponding four transition dipole moments are different for R2, R3, and R1* Feynman diagrams.
Normalized spectra for the four nonzero tensor elements for the technique $\mathbf{k}_{\mathrm{I}}$ are shown in Figure 22 for $t_{2}=0$ and in Figure 23 for $t_{1}=0$. Inspection of the corresponding Liouville space pathways reveals that diagonal peak intensities are identical for the $z z y y$, zyzy, and zyyz tensor elements, whereas the cross-peak intensities are only identical for zzyy and zyzy. Overtone and combinations band peak intensities for zzyy and zyzy are similar, though not identical. The $z z z z$ tensor element differs from the other three components. Thus, the combinations $z y z y-z y y z$, which can be obtained in a single measurement with the following choice of pulse polarizations $(0, \pi / 2,-\pi / 4, \pi / 4)$, and $z z y y-z y y z(0,-\pi / 4, \pi / 2, \pi / 4)$ are expected to eliminate the intense diagonal peaks, leaving only the important cross- 

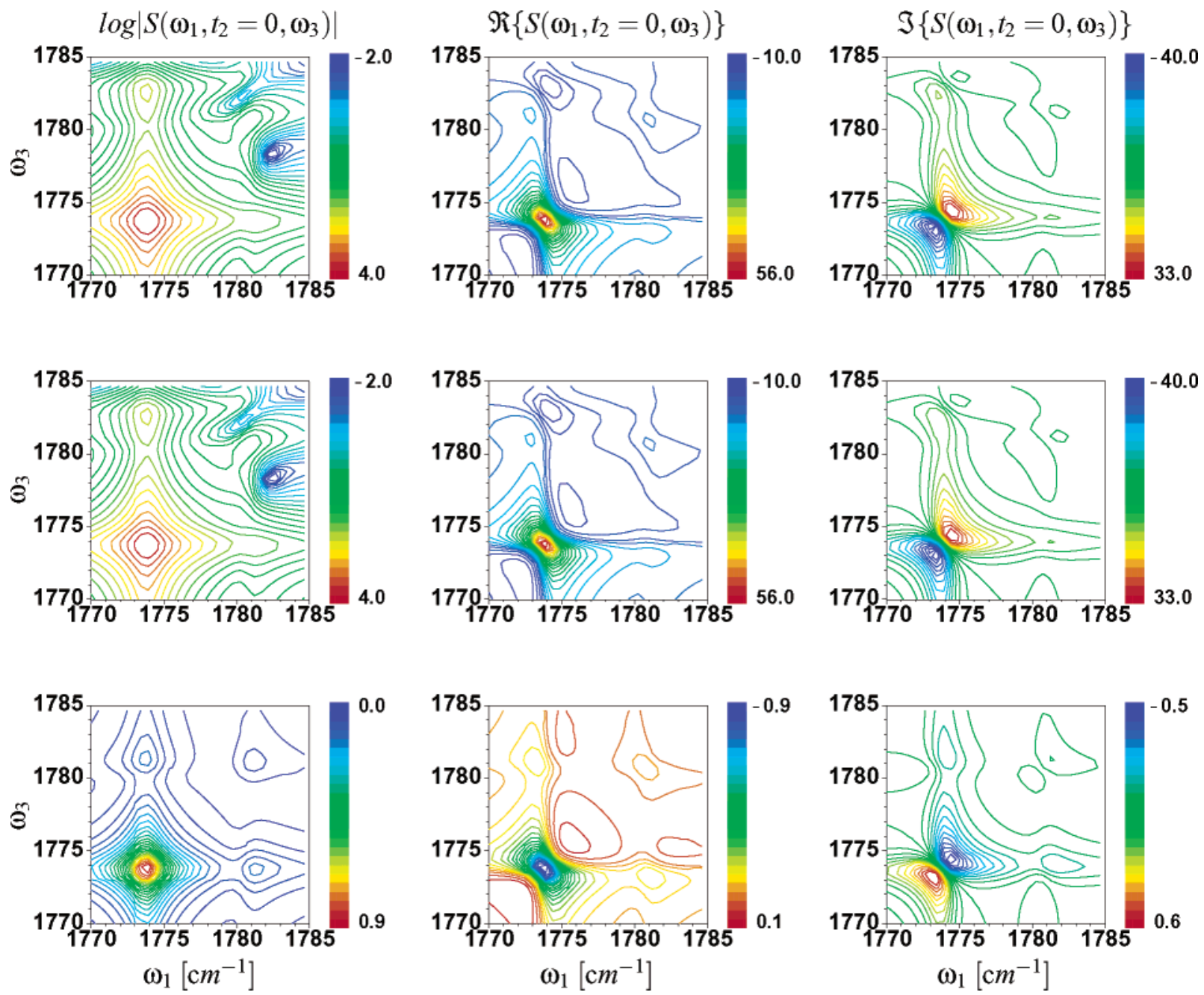

Figure 21. Cross-peak $(z z z z),\left(\Omega_{\mathrm{a}}, \Omega_{\mathrm{b}}\right)$ for $\bar{\omega}_{1}=\bar{\omega}_{2}=\bar{\omega}_{3}=1777 \mathrm{~cm}^{-1}(v(\mathrm{C}=\mathrm{O}))$. Upper panel: $\mathbf{k}_{\mathrm{II}}$. Middle panel: $\mathbf{k}_{\mathrm{III}}$. Lower panel: $\mathbf{k}_{\mathrm{III}}-\mathbf{k}_{\mathrm{II}}$.

TABLE 6: Angles (deg) between Transition Dipole Moments (Eigenstate Basis) Involved in the Calculation of One-Color $(v(\mathrm{C}=\mathrm{O})) k_{\mathrm{I}}$ Spectra for $\mathrm{R} 2, \mathrm{R} 3$, and $\mathrm{R} 1 *$ Feynman Diagrams

\begin{tabular}{|c|c|c|c|c|c|c|c|c|c|}
\hline \multicolumn{10}{|c|}{$\mathrm{R} 2$ and R3 } \\
\hline \multicolumn{4}{|c|}{ states } & \multicolumn{6}{|c|}{ angle between transition dipole moments } \\
\hline a & $\mathrm{b}$ & $\mathrm{c}$ & $\mathrm{d}$ & $(\mathrm{a} \rightarrow \mathrm{b}) /(\mathrm{a} \rightarrow \mathrm{c})$ & $(a \rightarrow b) /(b \rightarrow a)$ & $(\mathrm{a} \rightarrow \mathrm{b}) /(\mathrm{c} \rightarrow \mathrm{a})$ & $(a \rightarrow c) /(b \rightarrow a)$ & $(\mathrm{a} \rightarrow \mathrm{c}) /(\mathrm{c} \rightarrow \mathrm{a})$ & $(b \rightarrow a) /(c \rightarrow a)$ \\
\hline$|0\rangle$ & $\mathrm{C}=\mathrm{O}$ (as) & $\mathrm{C}=\mathrm{O}(\mathrm{s})$ & $|0\rangle$ & 89.8 & 0.0 & 89.8 & 89.8 & 0.0 & 89.8 \\
\hline$|0\rangle$ & $\mathrm{C}=\mathrm{O}(\mathrm{s})$ & $\mathrm{C}=\mathrm{O}$ (as) & $|0\rangle$ & 89.8 & 0.0 & 89.8 & 89.8 & 0.0 & 89.8 \\
\hline
\end{tabular}




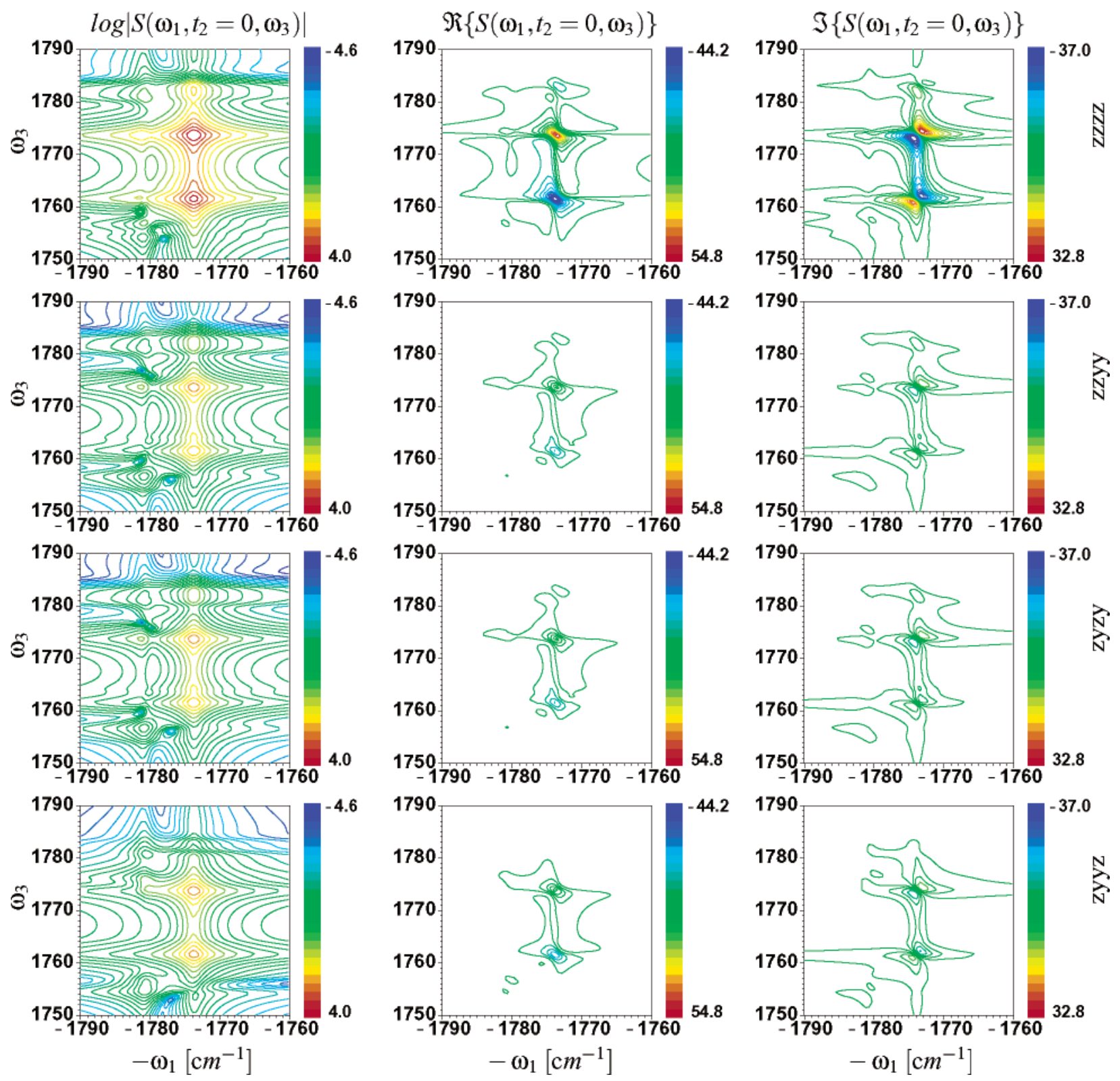

Figure 22. $\mathbf{k}_{\mathrm{I}}$ spectra with normalized intensities for tensor elements $z z z z, z z y y, z y z y$, and $z y y z$ (top to bottom). $\bar{\omega}_{1}=\bar{\omega}_{2}=\bar{\omega}_{3}=1777 \mathrm{~cm}^{-1}$ $(v(\mathrm{C}=\mathrm{O})), t_{2}=0$.

peaks. The former polarization condition has already been reported experimentally. ${ }^{23}$ Figures 24 and 25 show the respective $2 \mathrm{D}$ spectra. The $\left(-\omega_{1}, \omega_{3}\right)$ plots (upper panels) are very similar: The diagonal peaks are eliminated entirely, whereas the desired cross-peaks survive with equal intensities for both polarization conditions. Overtone and combination band peak patterns are also very similar, but not fully identical for both cases

The two polarization conditions differ considerably for the $\left(\omega_{2}, \omega_{3}\right)$ correlation plot (lower panels). For the combination $z y z y-z y y z(0, \pi / 2,-\pi / 4, \pi / 4)$ all resonances with frequencies $\omega_{2}=0$ cancel and only the peaks with $\omega_{2}= \pm\left(\Omega_{\mathrm{a}}-\Omega_{\mathrm{b}}\right)$ remain. For the combination zzyy-zyyz, however, only the two peaks at $\left(\Omega_{\mathrm{a}}-\Omega_{\mathrm{b}}, \Omega_{\mathrm{b}}\right)$ and $\left(\Omega_{\mathrm{b}}-\Omega_{\mathrm{a}}, \Omega_{\mathrm{a}}\right)$ cancel, whereas all other peaks show up.

2D zzyy-zyzy $(0,-\pi / 4, \pi / 4, \pi / 2)$ spectra are displayed in Figure 26. Diagonal peaks as well as cross-peaks cancel entirely in the $\left(-\omega_{1}, \omega_{3}\right)$ spectra (upper panels), leaving only the overtone and combination band peaks. There are no cancella- tions in the $\left(\omega_{2}, \omega_{3}\right)$ spectra (lower panels), but the relative intensities do change compared to the single tensor element spectra.

\section{Discussion}

We presented an ab initio procedure for simulating coherent three-pulse vibrational spectroscopies. Our calculations demonstrate how these experiments may be designed and analyzed using 2D correlation plots. Cross-peaks reveal the coupling between vibrational modes that may be used to gain structural information on molecules or chemical reactions with femtosecond time resolution. This information is not available from 1D spectra.

Density functional theory at the B3LYP functional level is well-known to yield very good agreement of calculated harmonic and experimental frequencies ${ }^{64-70}$ as well as reasonable agreement with respect to intensity patterns. ${ }^{71-74}$ We have therefore adopted this level of theory to calculate a complete 

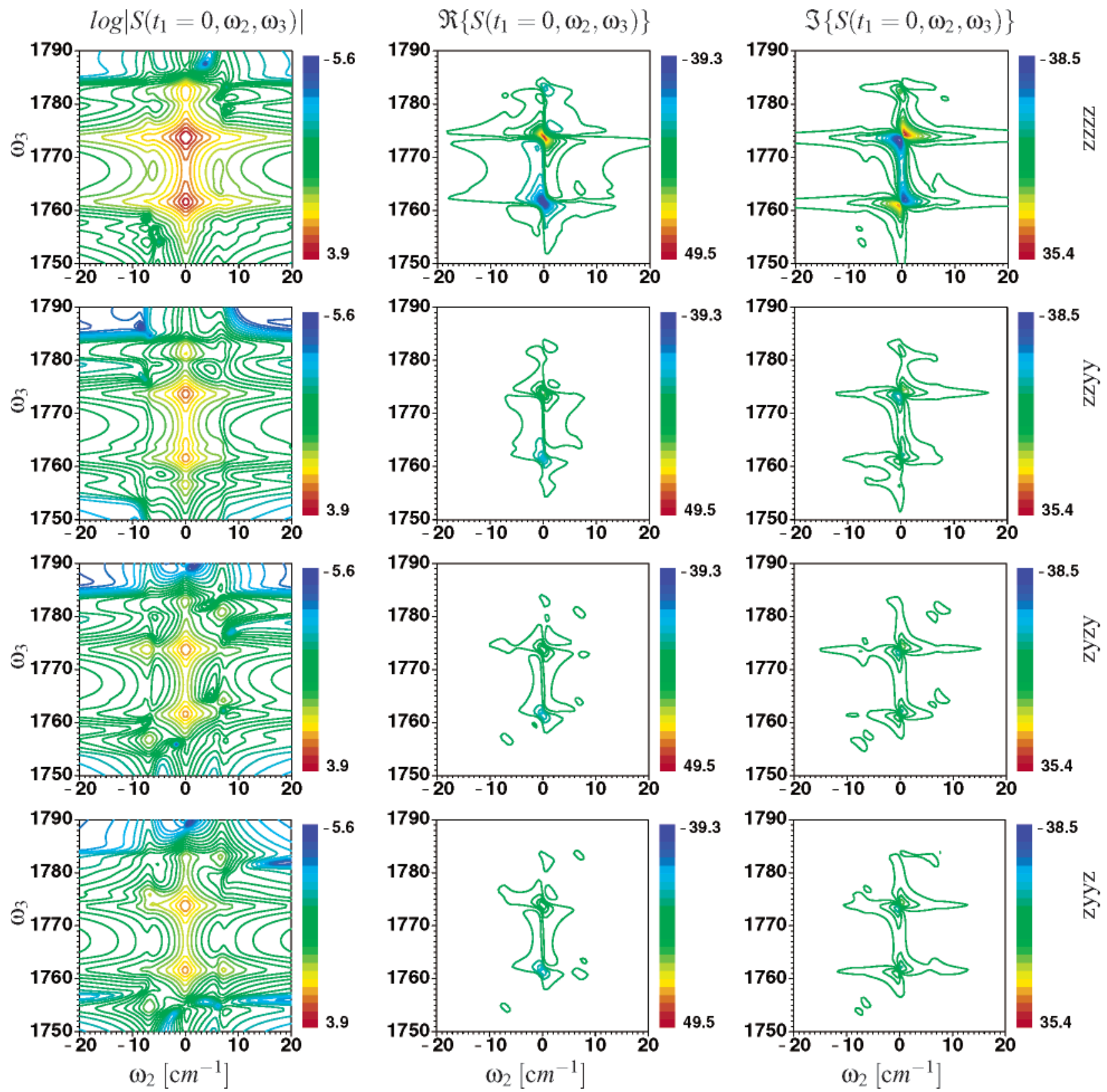

Figure 23. $\mathbf{k}_{\mathrm{I}}$ spectra with normalized intensities for tensor elements $z z z z, z z y y, z y z y$, and $z y y z$ (top to bottom). $\bar{\omega}_{1}=\bar{\omega}_{2}=\bar{\omega}_{3}=1777 \mathrm{~cm}^{-1}$ $(v(\mathrm{C}=\mathrm{O})), t_{1}=0$.

quartic anharmonic force field for the six coupled stretching vibrations $(\mathrm{N}-\mathrm{H}, \mathrm{C}=\mathrm{O}, \mathrm{C}-\mathrm{N})$ involved in the peptide bonds of a rigid bicyclic model dipeptide. The force field is expanded in internal coordinates to obtain an inherently local, and hopefully transferable, description of the vibrational modes. We compute eigenstate energies and eigenvectors from an effective anharmonic exciton Hamiltonian generated by distributing 10 excitation quanta among the six basis local modes. This results in 2153 states, 139 of which lie below $8000 \mathrm{~cm}^{-1}$, which is the frequency range covered by the spectroscopic techniques presented here.

The different coherent four-wave mixing techniques are classified by constructing all possible wavevector combinations of the three incoming pulses, which leads to four distinct signal directions that can be measured independently. We simulated one- and two-color $2 \mathrm{D}$ vibrational spectra at these wavevectors, either with all three pulses in resonance with the $v(\mathrm{C}=\mathrm{O})$ bands or with two resonant with the $v(\mathrm{C}=\mathrm{O})$ bands and one (either the second or the third) tuned to the $v(\mathrm{~N}-\mathrm{H})$ transitions. The one-color experiments reveal information on the coupling of amide I modes, which can be used to monitor the secondary structure of peptides and proteins and follow its fluctuations on ultrafast time scales. The two-color experiments yield the coupling of peptide $\mathrm{C}=\mathrm{O}$ and $\mathrm{N}-\mathrm{H}$ bonds, which provides additional insight into structural and dynamical properties. We further show that the Fermi resonance coupling observed in peptides between the amide II overtones and the $\mathrm{N}-\mathrm{H}$ stretching bands (amides A and B) can be directly monitored by a twocolor experiment measured in the $\mathbf{k}_{\mathrm{II}}$ direction with the pulses tuned to the respective bands.

2D spectra of multilevel vibrational systems contain a large number of peaks that are likely to overlap. In particular, the usually intense diagonal peaks often obscure the desired crosspeaks, which carry more detailed structural signatures. We therefore presented two methods that can be used to simplify the spectra: The superposition of single wavevector spectra, and the use of specific polarization configurations to select desired combinations of tensor components. Both procedures 

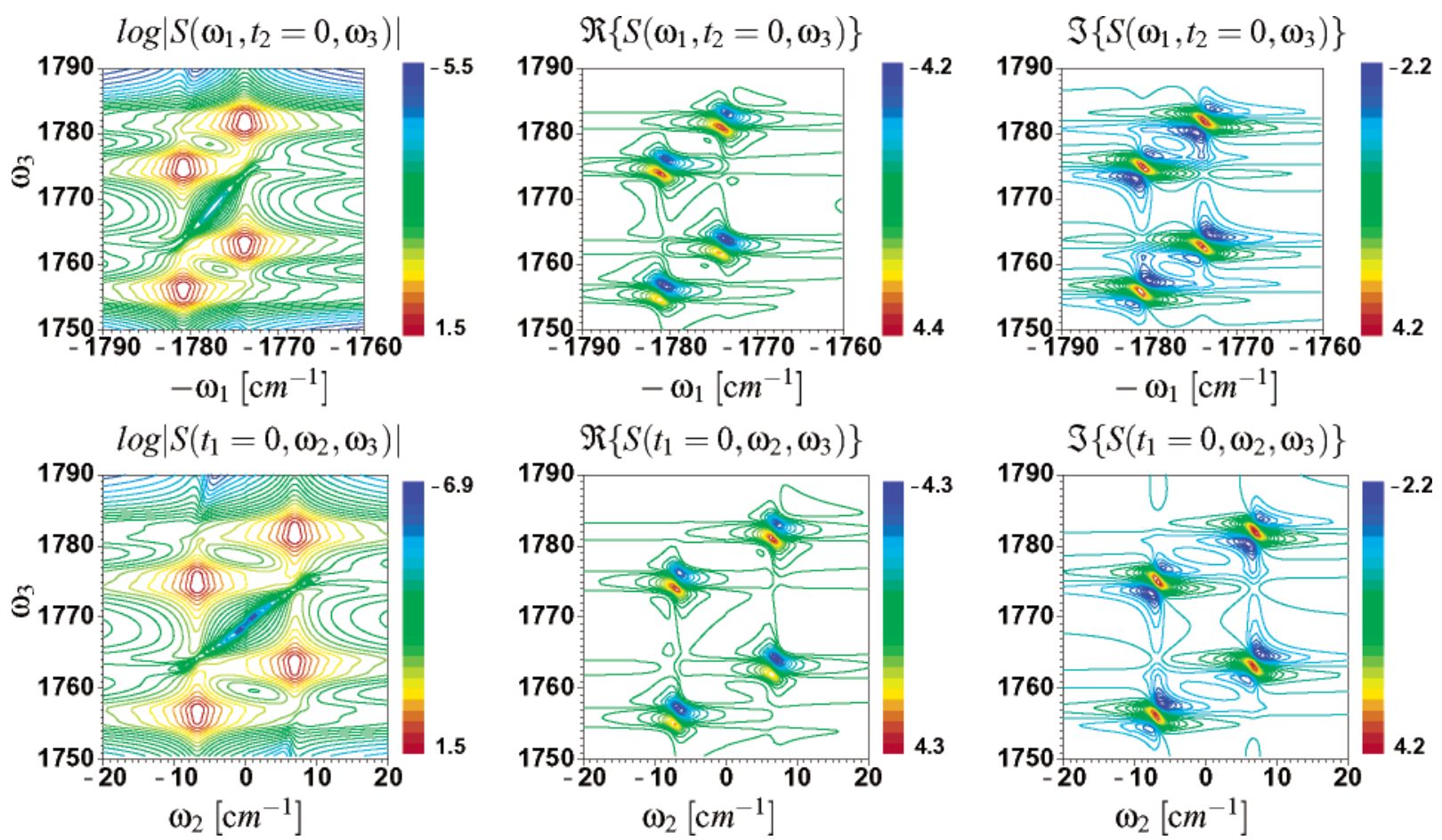

Figure 24. $\mathbf{k}_{\mathrm{I}}$ spectra for tensor elements $z y z y-z y y z=(0, \pi / 2,-\pi / 4, \pi / 4) . \bar{\omega}_{1}=\bar{\omega}_{2}=\bar{\omega}_{3}=1777 \mathrm{~cm}^{-1}(v(\mathrm{C}=\mathrm{O}))$. Upper panel: $t_{2}=0$. Lower panel: $t_{1}=0$.
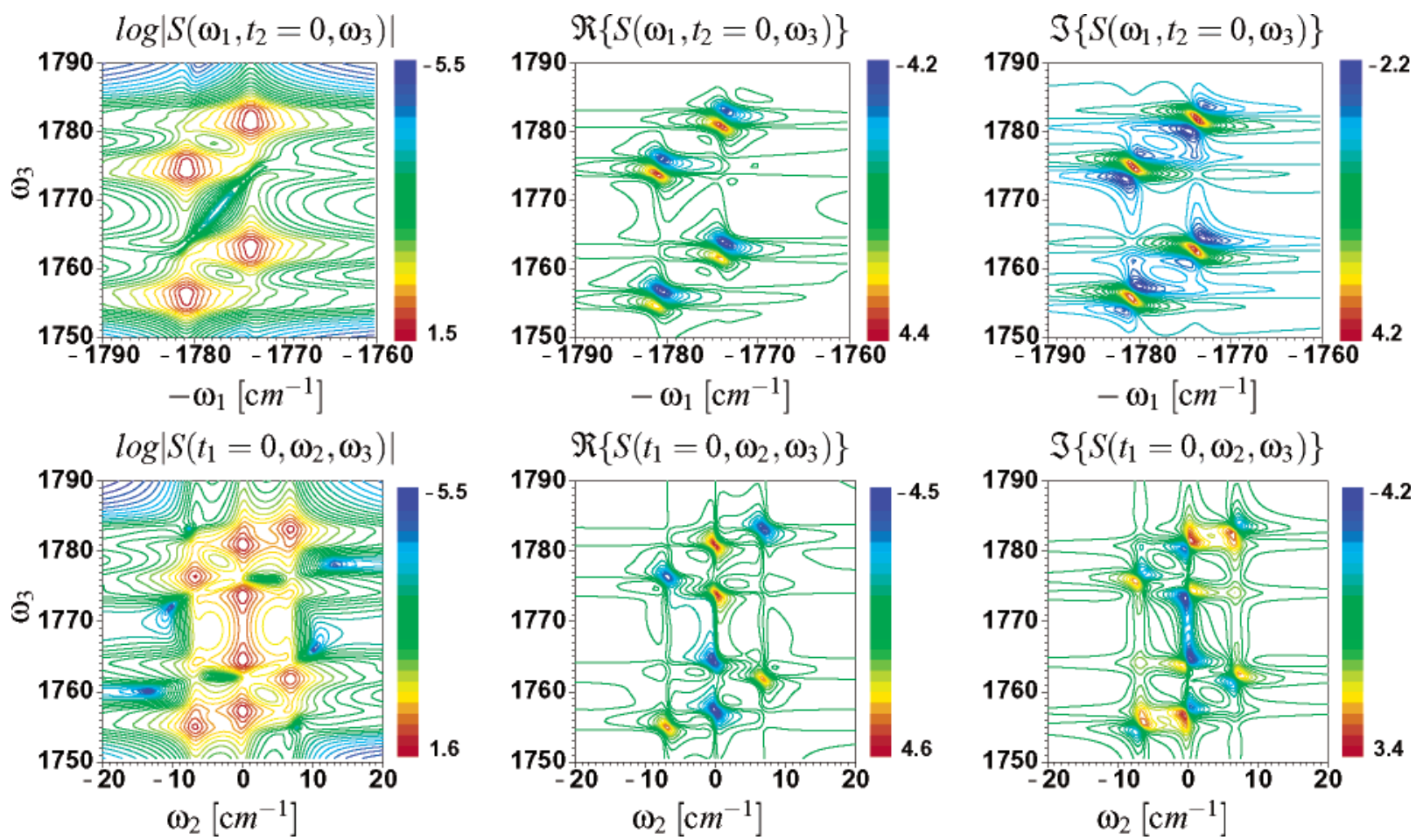

Figure 25. $\mathbf{k}_{\mathrm{I}}$ spectra for tensor elements $z z y y-z y y z=(0,-\pi / 4, \pi / 2, \pi / 4) . \bar{\omega}_{1}=\bar{\omega}_{2}=\bar{\omega}_{3}=1777 \mathrm{~cm}^{-1}(v(\mathrm{C}=\mathrm{O}))$. Upper panel: $t_{2}=0$. Lower panel: $t_{1}=0$.

can be applied to control or remove certain groups of peaks from the spectra, i.e., diagonal peaks, cross-peaks, or overtone peaks.

The present study focused on the calculation of the peak patterns. Future microscopic simulations of the line shapes should allow more realistic predictions of experimental spectra.
The present ab initio methodology for simulating coherent 2D vibrational spectra is directly applicable to small and medium-sized molecules. For larger systems, however, the quantum chemical calculations become too expensive. Therefore, different approaches that facilitate ab initio investigations of biologically relevant systems such as proteins or DNA must be developed. One possibility is to utilize high-level ab initio 

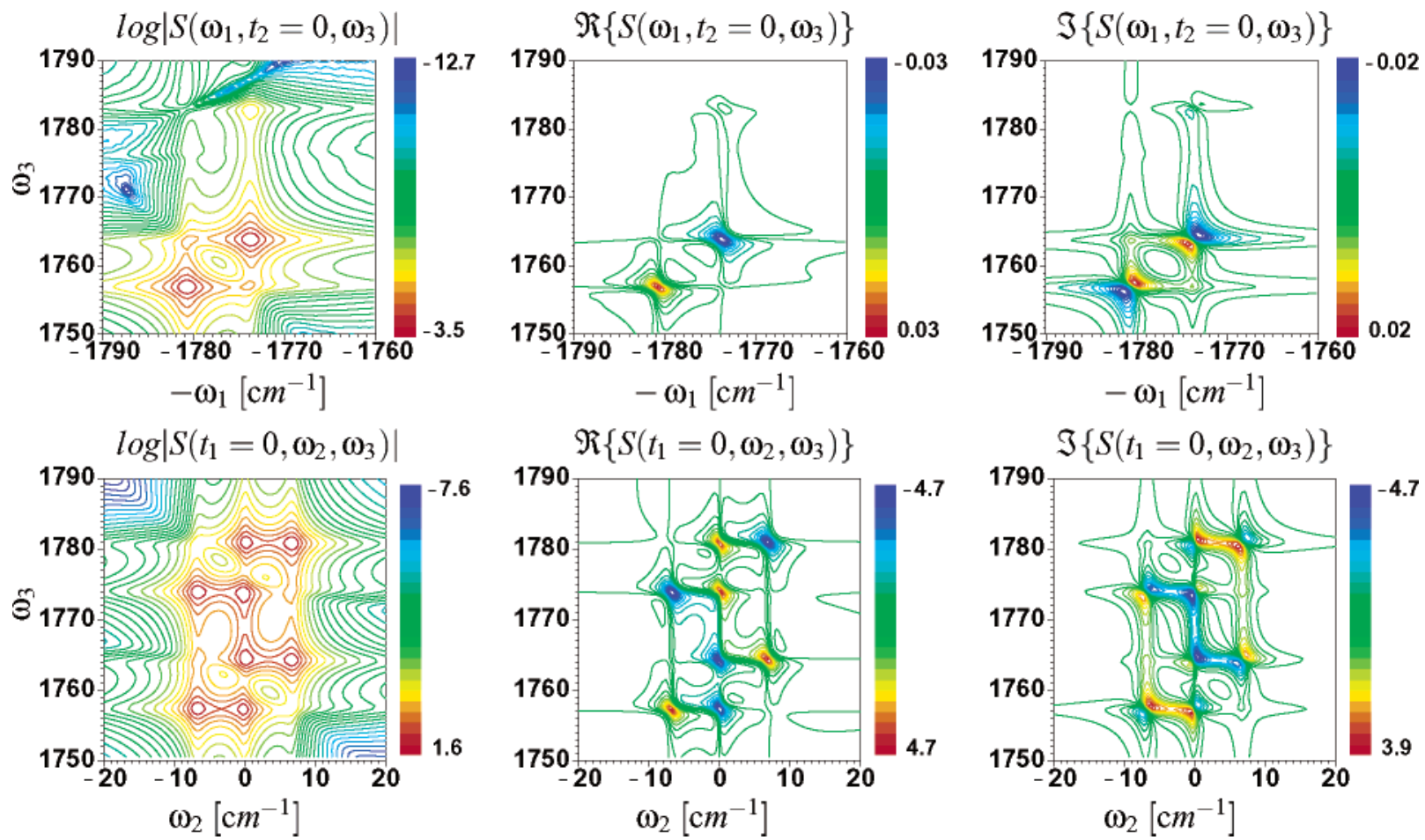

Figure 26. $\mathbf{k}_{\mathrm{I}}$ spectra for tensor elements $z z y y-z y z y=(0,-\pi / 4, \pi / 4, \pi / 2) . \bar{\omega}_{1}=\bar{\omega}_{2}=\bar{\omega}_{3}=1777 \mathrm{~cm}^{-1}(\nu(\mathrm{C}=\mathrm{O}))$. Upper panel: $t_{2}=0 . \mathrm{Lower}$ panel: $t_{1}=0$.

calculations performed on small subunits to derive parameters that can be used to parametrize the Hamiltonian for the entire system. ${ }^{75}$ The interaction between the subunits might be treated by simple models, for instance, dipole-dipole interactions. ${ }^{76}$

Acknowledgment. We wish to thank Professor Thomas Elsässer for useful discussions. The support of The National Institutes of Health grant no. RO1 GM59230-01A2 and the National Science Foundation grant no. CHE-0132571 is gratefully acknowledged. J.D. thanks the Max-Kade foundation for financial support of his stay in Rochester.

\section{References and Notes}

(1) Mukamel, S.; Pyriatinski, A.; Chernyak, V. Acc. Chem. Res. 1999 32,145

(2) Mukamel, S. Апnи. Rev. Phys. Chem. 2000, 51, 691

(3) Mukamel, S., Hochstrasser, R., Eds. Chem. Phys. 2001, 135 (special issue).

(4) Elsaesser, T., Mukamel, S., Murnane, M., Scherer, N. F., Eds. Ultrafast Phenomena XII; Springer Series in Chemical Physics; Berlin, Heidelberg, 2001.

(5) Baumert, T.; Brixner, T.; Seyfried, V.; Strehle, M.; Gerber, G. Appl. Phys. B 1997, 65, 779-792.

(6) Brixner, T.; Gerber, G. Opt. Lett. 2001, 26, 557-559.

(7) Krimm, S.; Bandekar, J. Adv. Protein Chem. 1986, 38, 181

(8) Stuart, B., Ed. Biological applications of infrared spectroscopy; J. Wiley \& Sons: New York, 1997.

(9) Lee, S.; Mirkin, N.; Krimm, S. Biopolymers 1989, 49, 195

(10) Hamm, P.; Lim, M. H.; Hochstrasser, R. M. J. Phys. Chem. B 1998, 102,6123 .

(11) Hamm, P.; Lim, M.; DeGrado, W. F.; Hochstrasser, R. M. Proc. Natl. Acad. Sci. U.S.A. 1999, 96, 2036

(12) Zhao, W.; Wright, J. C. Phys. Rev. Lett. 2000, 84, 1411.

(13) Asplund, M. C.; Zanni, M. C.; Hochstrasser, R. M. Proc. Natl. Acad. Sci. U.S.A. 2000, 97, 8219

(14) Asplund, M. C.; Lim, M.; Hochstrasser, R. M. Chem. Phys. Lett. 2000, 323, 269

(15) Hamm, P.; Lim, M.; DeGrado, W. F.; Hochstrasser, R. M. J. Chem. Phys. 2000, 112, 1907.

(16) Hochstrasser, R. M.; Hamm, P.; Lim, M.; Ge, N.-H.; deGrado, W. F. Biophys. J. 2000, 78, 76 .

(17) Tokmakoff, A. J. Phys. Chem. A 2000, 104, 4247-4255.
(18) Woutersen, S.; Hamm, P. J. Phys. Chem. B 2000, 104, 11316.

(19) Woutersen, S.; Hamm, P. J. Chem. Phys. 2001, 114, 2727.

(20) Woutersen, S.; Mu, Y.; Stock, G.; Hamm, P. Proc. Natl. Acad Sci. U.S.A. 2001, 98,11254

(21) Woutersen, S.; Mu, Y.; Stock, G.; Hamm, P. Chem. Phys. 2001, 266,137

(22) Zanni, M. C.; Asplund, M. C.; Hochstrasser, R. M. J. Chem. Phys. 2001, 114, 4579 .

(23) Zanni, M. T.; Ge, N.-H.; Kim, Y. S.; Hochstrasser, R. M. Proc. Natl. Acad. Sci. U.S.A. 2001, 98, 11265.

(24) Zanni, M. T.; Apslund, M. C.; Decatur, S. M.; Hochstrasser, R. M. Springer Ser. Chem. Phys. 2001, 66, 504.

(25) Zanni, M. T.; Gnanakaran, S.; Stenger, J.; Hochstrasser, R. M. J. Phys. Chem. B 2001, 105, 6520

(26) Hochstrasser, R. M. Chem. Phys. 2001, 266, 273.

(27) Hamm, P.; Hochstrasser, R. M. In Ultrafast Infrared and Raman Spectroscopy; Fayer, M. D., Ed.; Marcel Dekker: New York, 2001; pp 273247.

(28) Golonzka, O.; Khalil, M.; Demirdöven, N.; Tokmakoff, A. J. Chem. Phys. 2001, 115, 10814.

(29) Gnanakaran, S.; Hochstrasser, R. M. J. Am. Chem. Soc. 2001, 123 , 12886

(30) Khalil, M.; Tokmakoff, A. Chem. Phys. 2001, 266, 213.

(31) Ge, N.-H.; Hochstrasser, R. M. Phys. Chem. Commun. 2002, 5 , 17.

(32) Ge, N.-H.; Zanni, M. T.; Hochstrasser, R. M. J. Phys. Chem. A 2002, 106, 962

(33) Hochstrasser, R. M.; Ge, N.-H.; Gnanakaran, S.; Zanni, M. T. Bull. Chem. Soc. Jpn. 2002, 75, 1103.

(34) Rubtsov, I. V.; Hochstrasser, R. M. J. Phys. Chem. B 2002, 106 , 9165.

(35) Scheurer, C.; Mukamel, S. J. Chem. Phys. 2001, 115, 4989.

(36) Scheurer, C.; Mukamel, S. Bull. Chem. Soc. Jpn. 2002, 75, 989.

(37) Onuchic, B. J. N.; Wolynes, P. G.; Luthey-Schulten, Z. Proc. Natl. Acad. Sci. U.S.A. 1995, 92, 3626.

(38) Dobson, C. C. M.; Sali, A.; Karplus, M. Angew. Chem., Int. Ed. 1998, 37, 868

(39) Brooks, A. C. L., III; Onuchic, B. J. N.; Wales, D. J. Science 2001, 293,612 .

(40) Wüthrich, K. NMR of Proteins and Nucleic Acids; J. Wiley \& Sons: New York, 1986.

(41) Mu, D. Y.; Kosov, D. S.; Stock, G. J. Phys. Chem. A, submitted for publication.

(42) van der Spoel, D. Biochem. Cell. Biol. 1998, 76, 164.

(43) Besley, N. A.; Brienne, M.-J.; Hirst, J. D. J. Phys. Chem. B 2000 104,12371 
(44) Moran, A. M.; Dreyer, J.; Mukamel, S. J. Chem. Phys. 2003, 118 1347.

(45) Mukamel, S. Principles of nonlinear optical spectroscopy; Oxford University Press: New York, Oxford, 1995.

(46) Venkatramani, R.; Mukamel, S. J. Chem. Phys. 2002, 117, 11089.

(47) Golonzka, O.; Tokmakoff, A. J. Chem. Phys. 2001, 115, 297.

(48) Barron, L. D., Ed. Molecular Light Scattering and Optical Activity; Cambridge University Press: Cambridge, U.K., 1982.

(49) Equation 13 in ref 26.

(50) Monson, P. R.; McClain, W. M. J. Chem. Phys. 1970, 53, 29.

(51) Lee, C.; Yang, R. G.; Parr, W. Phys. Rev. B 1988, 37, 785.

(52) Miehlich, B.; Savin, A.; Stoll, H.; Preuss, H. Chem. Phys. Lett 1989, 157,200

(53) Becke, A. D. J. Chem. Phys. 1993, 98, 5648.

(54) Hertwig, R. H.; Koch, W. Chem. Phys. Lett. 1997, 268, 345.

(55) Hehre, W. J.; Ditchfield, R.; Pople, J. A. J. Chem. Phys. 1971, 54 724.

(56) Hehre, W. J.; Ditchfield, R.; Pople, J. A. J. Chem. Phys. 1972, 56, 2257.

(57) Hariharan, P. C.; Pople, J. A. Theor. Chim. Acta 1973, 28, 13.

(58) Hariharan, P. C.; Pople, J. A. Mol. Phys. 1974, 27, 209.

(59) Gordon, M. S. Chem. Phys. Lett. 1980, 76, 163.

(60) Frisch, M. J.; Trucks, G. W.; Schlegel, H. B.; Scuseria, G. E.; Robb, M. A.; Cheeseman, J. R.; Zakrzewski, V. G.; Montgomery, J. A.; Stratmann, R. E.; Burant, J. C.; Dapprich, S.; Millam, J. M.; Daniels, A. D.; Kudin, K. N.; Strain, M. C.; Farkas, O.; Tomasi, J.; Barone, V.; Cossi, M.; Cammi, R.; Mennucci, B.; Pomelli, C.; Adamo, C.; Clifford, S.; Ochterski, J.; Petersson, G. A.; Ayala, P. Y.; Cui, Q.; Morokuma, K.; Malick, D. K.; Rabuck, A. D.; Raghavachari, K.; Foresman, J. B.; Cioslowski, J.; Ortiz, J. V.; Stefanov, B. B.; Liu, G.; Liashenko, A.; Piskorz, P.; Komaromi, I.;
Gomperts, R.; Martin, R. L.; Fox, D. J.; Keith, T.; Al-Laham, M. A.; Peng, C. Y.; Nanayakkara, A.; Gonzalez, C.; Challacombe, M.; Gill, P. M. W.; Johnson, B. G.; Chen, W.; Wong, M. W.; Andres, J. L.; Head-Gordon, M.; Replogle, E. S.; Pople, J. A. Gaussian 98, Revision A.9; Gaussian, Inc.: Pittsburgh, PA, 1998.

(61) Brazhnikov, E.; Chirgadze, Y. J. Mol. Biol. 1978, 122, 127.

(62) Mirkin, N.; Krimm, S. J. Am. Chem. Soc. 1991, 113, 9742.

(63) Golonzka, O.; Khalil, M.; Demirdöven, N.; Tokmakoff, A. Phys. Rev. Lett. 2001, 86, 2154.

(64) Matsuura, H.; Yoshida, H. in Handbook of vibrational spectroscopy; Wiley: Chichester, 2002; vol. 3, pp 2012-2028.

(65) Johnson, B. G.; Gill, P. M. W.; Pople, J. A. J. Chem. Phys. 1993 98,5612 .

(66) Rauhut, G.; Pulay, P. J. Phys. Chem. 1995, 99, 3093.

(67) Scott, A.; Radom, L. J. Phys. Chem. 1996, 100, 16502

(68) Wong, M. W. Chem. Phys. Lett. 1995, 256, 391.

(69) Yoshida, H.; Ehara, A.; Matsuura, H. Chem. Phys. Lett. 2000, 325, 477.

(70) Yoshida, H.; Takeda, K.; Okamura, J.; Ehara, A.; Matsuura, H. J Phys. Chem. 2002, 106, 3580.

(71) Galabov, B. S.; Dudev, T. Vibrational intensities; Elsevier Science: Amsterdam, 1996; Vol. 22.

(72) Yamaguchi, Y.; Frisch, M.; Gaw, J.; Schaefer, H., III; Binkley, J. J. Chem. Phys. 1986, 84, 2262.

(73) Galabov, B.; Bobadova-Parvanova, P.; Dudev, T. J. Mol. Struct. 1997, 406, 119.

(74) Galabov, B.; Yamaguchi, Y.; Remington, R. B.; Schaefer, H. F., III. J. Phys. Chem. A 2002, 106, 819.

(75) Moran, A. M.; Park, S.-M.; Dreyer, J.; Mukamel, S. J. Chem. Phys. 2003, 118, 3651 .

(76) Cha, S.; Ham, S.; Cho, M. J. Chem. Phys. 2002, 117, 740. 